\title{
NUMERICAL STUDY ON SHEAR BEHAVIOUR OF ENHANCED C-CHANNELS IN STEEL-UHPC-STEEL SANDWICH STRUCTURES
}

\author{
Chang-Hui Li ${ }^{1}$, Jia-Bao Yan ${ }^{2,}{ }^{*}$, Hui-Ning Guan ${ }^{2,3}$ and Hong-Long Wang ${ }^{3}$ \\ ${ }^{1}$ School of Transportation Science and Engineering \& Airport engineering research base, Civil Aviation University of China,Tianjin 300300, China \\ ${ }^{2}$ School of Civil Engineering, Tianjin University, Tianjin 300350, China \\ ${ }^{3}$ Tianjin Municipal Engineering Design \& Research Institute, Tianjin 300392, China \\ *(Corresponding author: E-mail: ceeyanj@163.com)
}

\section{A B S T RA C T}

This paper firstly developed a three-dimensional (3D) finite element model (FEM) for enhanced C-channels (ECs) in steelUHPC-steel sandwich structures (SUSSSs). The FEM was validated by 12 push-out tests on ECs with UHPC. With the validated FEM, this paper performed in-depth parametric studies on shear behaviours of ECs with ultra-high performance concrete (UHPC). These investigated parameters included bolt-hole gap $(a)$, grade $(\mathrm{M})$ and diameter $(d)$ of bolt, core strength $\left(f_{\mathrm{c}}\right)$, length of C-channel $\left(L_{\mathrm{c}}\right)$, and prestressing force ratio on bolt $(\rho)$ in ECs. Under shear forces, the ECs in UHPC exhibited successive fractures of bolts and C-channels. Increasing the bolt-hole gap within 0-2 mm has no harm on the ultimate shear resistance, but greatly improves the slip capacity of ECs. Increasing grade and diameter of bolts improves the shear resistance and ductility of ECs through increasing the $P_{\mathrm{B}} / P_{\mathrm{C}}$ (shear strength of bolt to that of C-channel) ratio. Increasing the core strength increased the shear resistance, but reduced the ductility of ECs due to the reduced $P_{\mathrm{B}} / P_{\mathrm{C}}$ ratio. The ECs with $L_{\mathrm{c}}$ value of $50 \mathrm{~mm}$ offer the best ductility. Prestressing force acting on the bolts reduced the shear strength and ductility of ECs with UHPC. Analytical models were proposed to estimate the ultimate shear resistance and shear-slip behaviours of ECs with UHPC. The extensive validations of these models against 12 tests and 31 FEM analysis cases proved their reasonable evaluations on shear behaviours of ECs with UHPC.

Copyright $\odot 2021$ by The Hong Kong Institute of Steel Construction. All rights reserved.
A R T I C LE H ISTORY

$\begin{array}{ll}\text { Received: } & \text { 24 January } 2021 \\ \text { Revised: } & \text { 4 May } 2021 \\ \text { Accepted: } & \text { 4 May } 2021\end{array}$

\section{K E Y W O R D S}

Steel-concrete-steel sandwich structure;

Connectors;

Finite element;

Push-out tests:

Shear strength;

Damage plasticity model;

Composite structure;

ABAQUS.

\section{Introduction}

The applications of steel-concrete-steel (SCS) sandwich structures (SCSSSs) as the high performance structural members in engineering constructions keep increasing in recent several decades. This relative new type of structure, consisting of two faceplates and a sandwiched core, was firstly used as the undersea cylindrical shell oil containers [1]. Due to the extensive advantages received, e.g., relatively high structural performance, savings of formworks for casting, and reducing detailing works, the application of SCSSSs was gradually extended to the bridge deck [2], immersed tunnels [3], shear walls for nuclear constructions [4] and skyscraper [5], shielding tunnels [6], and protective structures against impact and blast loadings [7-9]. Recently, ultrahigh performance concrete (UHPC) with a compressive strength over $120 \mathrm{MPa}$ has been developed and used in the SCSSSs, i.e., steel-UHPC-steel sandwich structures (SUSSSs), e.g., SUSSS developed for nuclear constructions [10] and high-rise buildings [11].

Since the SCSSS (or SUSSS) is a composite structure with a multi-layer cross section, the bonding measures act essentially on the structural composite action. Adhesive or mechanical bonding was usually taken in SCSSS/SUSSS structure. The typical adhesive bonding (e.g., epoxy) proved to be effective on improving the steel-concrete bonding in SCSSSs [12], and its critical disadvantage is that it could not provide cross-sectional shear resistance [13]. According to the linking methods of the two faceplates in SCSSSs/SUSSSs, there are three types of mechanical shear connectors, namely indirect link, direct link, and semi-direct link connectors [13]. The direct link connectors mainly connect the two faceplates in a direct way, e.g., through bolt connectors [14], friction-welded connectors [15], and laser-welded connectors [16]. These direct-link connectors tend to be very costing that brings difficulties on their applications in civil engineering infrastructures, e.g., friction-welded connectors. Moreover, the dimensions of the SCSSSs/SUSSSs with the laser/friction- welded connectors were restricted by the welding equipment, e.g., the thickness of friction-welded SCSSSs/SUSSSs was restricted within 0.2-0.7 m. The indirect-link connectors bond these three layers of materials through welding the connectors to faceplates and their embedment in concrete. Overlapped headed studs [17], angles and C-channels [18] are the typical indirect-link connectors. The transparent disadvantage of these indirect-link connectors is that their bonding effects greatly depend on the integrity of core. The spalled core would lose the bonding and greatly reduce the load carrying capacity of SCSSSs/SUSSS with such type of connectors. Double J-hooks [7] are representative semi-direct link connectors that their bonding is partially achieved through direct mechanical interlocking and partially through their embedment in the concrete core. However, these semi-direct link connectors (e.g. J-hooks) may cause the assembling difficulties. Thus, it is of importance to develop direct-link connectors with relative low costing. Enhanced Cchannels (ECs) (see Fig. 1) make up this blank, which possess strong faceplateconcrete interfacial bonding, but low costing [19]. Previous studies on SCSSSs/SUSSSs with ECs (SCSSS-EC/SUSSS-EC) concentrated on shear behaviours of ECs in normal weight concrete (NWC) [19], structural behaviours of SUSSS beams with ECs [20-21], and compressive behaviours of SUSSS walls with ECs [22]. However, as the key components in the SUSSS-ECs, the in-depth studies on shear behaviour of ECs in the UHPC have not been performed. It becomes necessary to carry out in-depth studies on shear behaviours of ECs in SUSSS-ECs and investigated their key influencing parameters.
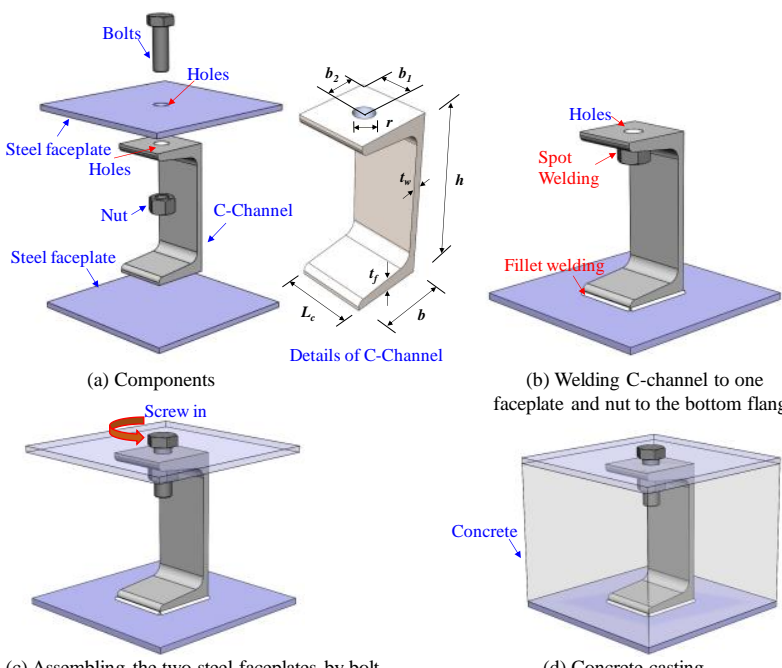

(b) Welding C-channel to one faceplate and nut to the bottom flange

(c) Assembling the two steel faceplates by bolt

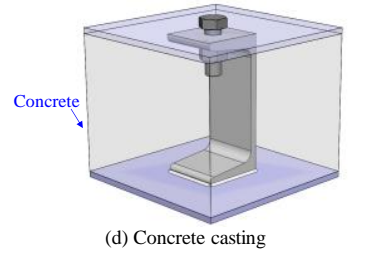

Fig. 1 Details of Enhanced C-channel (EC) connectors in SCSSS

This paper is a companion study of the tests on shear behaviours of ECs in UHPC using the numerical simulation method. A detailed 3D finite element model (FEM), adopting the continuum damage material models, was firstly developed to simulate the ECs in SUSSS-ECs. Twelve push-out tests on ECs in UHPC were used for the validations of FEM simulation. With the validated FEM, shear behaviour of ECs in UHPC was studied as well as their key influencing parameters. Finally, analytical models were proposed for shear-slip behaviour and ultimate shear resistance of ECs in the UHPC. 


\section{Push-out tests on ECs in SUSSS-ECs}

\subsection{Details of ECs in SUSSS-ECS}

The developed ECs in SUSSS-ECs is plotted in Fig. 1. The main components in each EC are a C-channel, an externally-screwed bolt, and a nut. Before the fabrication, the holes in the top flange of the $\mathrm{C}$-channel and its connecting faceplate were drilled as shown in Fig. 1(a). After that, the bottom flange of the $\mathrm{C}$-channel is connected to the bottom faceplate using fillet welding, and the nut was attached to the bottom surface of top flange of C-channel using the spot welding [see Fig. 1(b)]. After installation of the top faceplate through externally-screwed bolts [see Fig. 1(c)], concrete casting ends the fabrication procedures of ECs [see Fig. 1(d)].

\subsection{Push-out tests on ECs in SUSSSs}

Twelve push-out tests were performed on ECs that simulate a segment of the SUSSSs. Fig. 2 illustrates details of a specimen for push-out test that include two pairs of ECs, faceplates, UHPC block, and reinforcement mesh. These 12 specimens with the same two specimens in one group can be categorized into six groups regarding their designed different parameters, namely U1 U6 (The two specimens for each group were denoted as -A or -B, e.g., U1A and U1B for group one specimens). The studied parameters were the length of $\mathrm{C}$-channel flange $\left(L_{\mathrm{c}}\right)$, depth of C-channel $(h)$, and layout of C-channel. Specimens U1A/B, $\mathrm{U} 2 \mathrm{~A} / \mathrm{B}$, and $\mathrm{U} 3 \mathrm{~A} / \mathrm{B}$ were prepared with $\mathrm{Lc}$ values of 50,30 , and $70 \mathrm{~mm}$ to check the influence of Lc. Specimens U1A/B, U4A/B and U5A/B were prepared with different $\mathrm{h}$ of 120,100 , and $140 \mathrm{~mm}$, respectively. Specimens U1A/B and $\mathrm{U} 6 \mathrm{~A} / \mathrm{B}$ were designed with different layout of the C-channels, i.e., the web of the C-channel was horizontally or vertically installed.

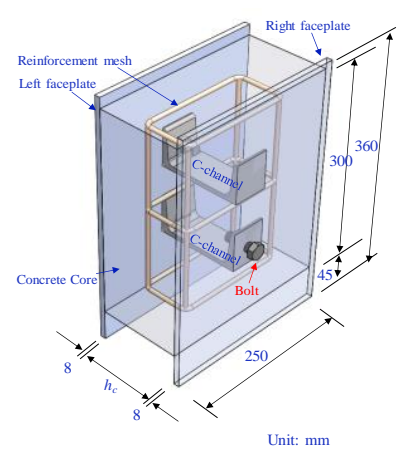

(a) 3D-view

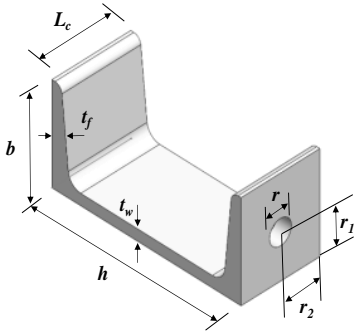

(c) Details of C-channels used in the push-out tests

2 Geometry of SUSSS with ECs

The geometry of the push-out test specimen is depicted in Fig. 2(a)-(b). Fig. 2(c) illustrates the geometry of different $\mathrm{C}$-channels used in the push-out test specimens. The UHPC was used in the push-out test specimen, and its mix proportions equal to 898: 202: 225: $988: 270: 17 \mathrm{~kg} / \mathrm{m}^{3}$ for cement: water: silica fume: quartz sand: quartz powder: superplasticizer. More detailed information on mechanical properties of UHPC are given by Yan et al. [20-22] and Zhu et al. [23]. Fig. 3 shows the UHPC compression/tensile stress-strain curves.

The 8mm-thick faceplates in the push-out test specimens adopted Q345 mild steel with a yield strength of $355 \mathrm{MPa}$. Chinese standard M8.8 bolts and mild steel Q235B C-channels with different heights of 100, 120, and $140 \mathrm{~mm}$ were used in ECs. The tensile stress-strain curves of involved bolts and Cchannels are given in Fig. 4(a). The reinforcement mesh adopts the $\phi 8 \mathrm{~mm}$ HRB400 rebar with a yield strength of $400 \mathrm{MPa}$.
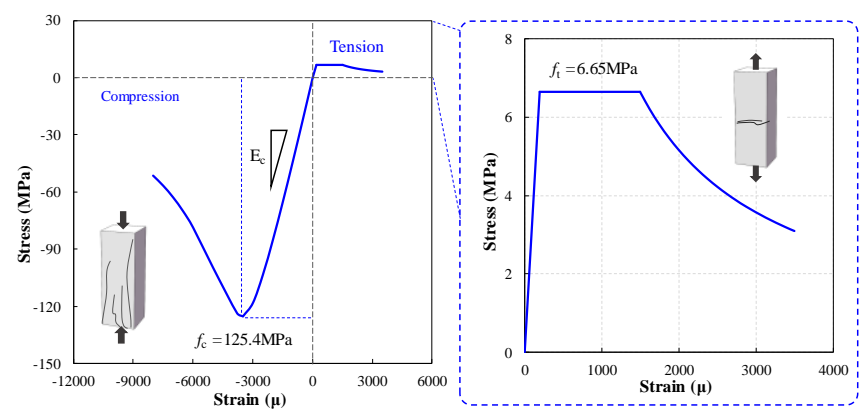

Fig. 3 Uniaxial compressive and tensile stress-strain curves of UHPC
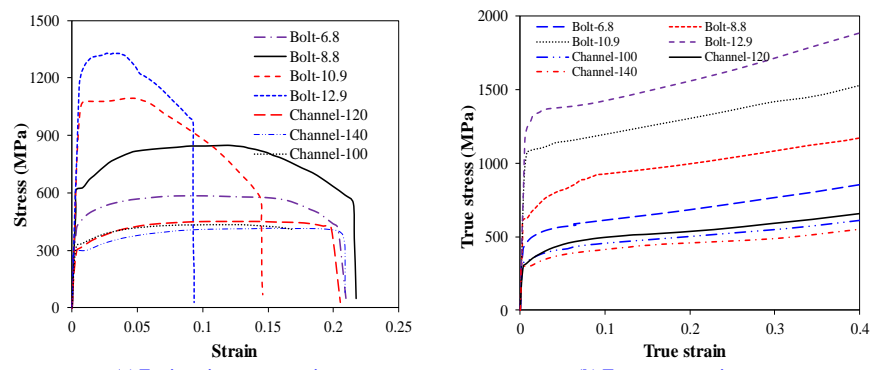

(a) Engineering stress-strain curve
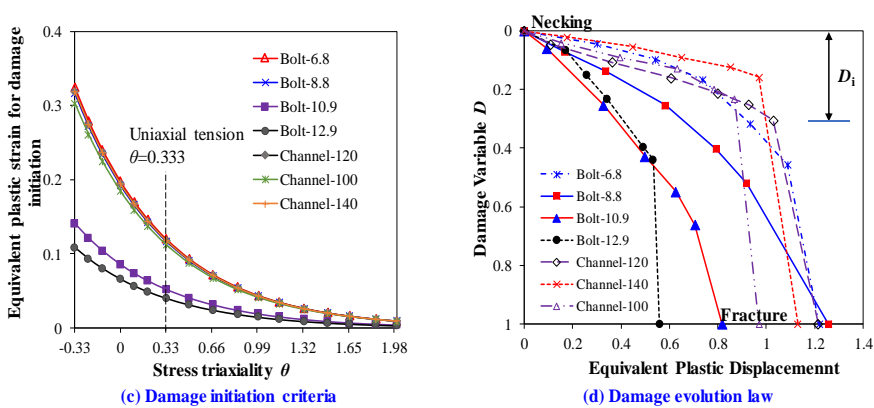

Fig. 4 Engineering and true stress-strain curve, damage initiation laws, and damage

evovution laws for DPM of steel materials

\subsection{Test setup}

The testing setup of push-out tests on ECs in UHPC is illustrated in Fig. 5. The specimens were directly put on the rigid base, and only loaded on the centre UHPC core in the displacement mode. Thus, the concrete-faceplate interfacial slips at the top and bottom of specimens were measured by four LVDTs working in pairs. The reaction force of the specimen was instrumented by the load cell integrated in the testing machine.

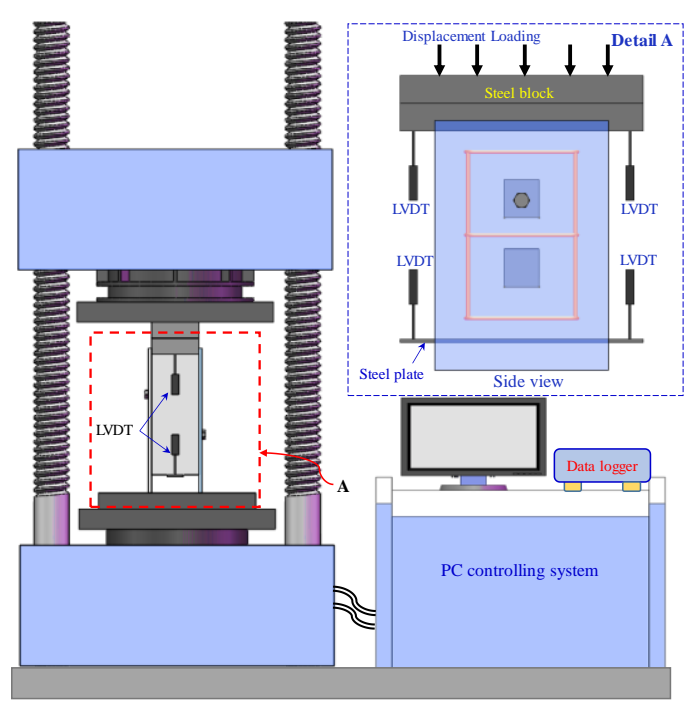




\section{Finite element model (FEM) on push-out tests on ECs}

\subsection{Introductions on FEM}

The developed FEM for push-out tests with UHPC and ECs adopted general commercial software ABAQUS/CAE [24]. Fig. 6 shows the developed FEM. It detailed simulates the push-out test specimens using a $1 / 2$ model considering the symmetric geometry and loading pattern. Different components were detailed modelled, e.g, the steel faceplates, reinforcement mesh, C-channel, bolt, UHPC core, base plate and the loading platen. Considering the influences of the local geometry and channel-UHPC core interaction on shear behaviours of ECs, the holes were reserved in the overlapped positions between the $\mathrm{C}$ channel and the core [see Fig. 6(d)].

Regarding the solution of the FE analysis (FEA), ABAQUS/Explicit solver was used in this FE simulation [24].
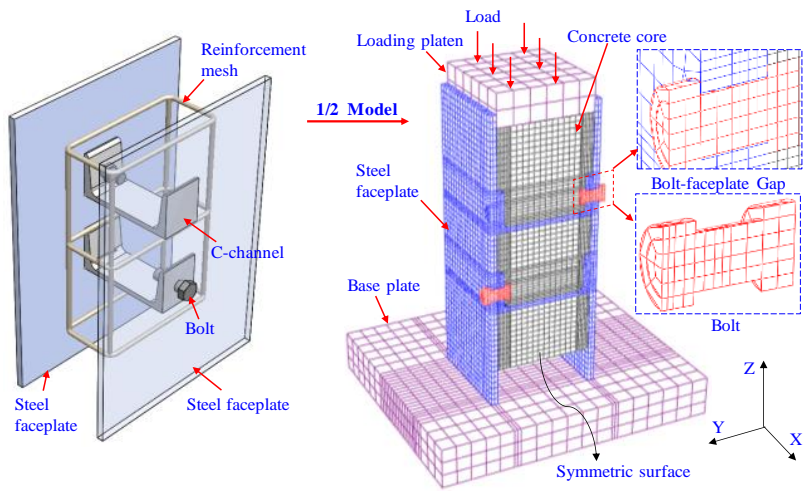

(a) Push-out test specimen

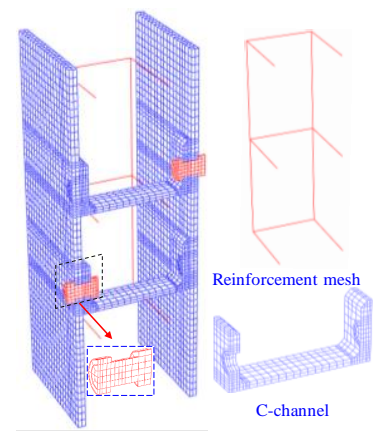

(c) Steel components in FEM

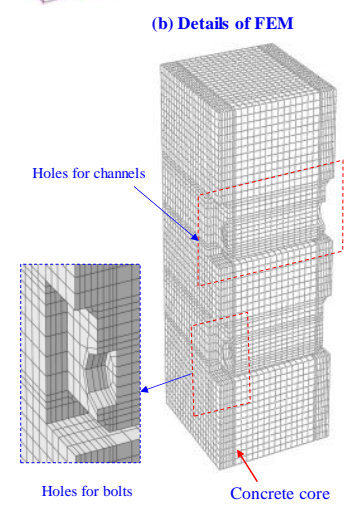

(d) Concrete core in FEM
Fig. 6 FEM for push-out test specimen with ECs

\subsection{Material models of steels}

The steel faceplates and reinforcements adopt the nonlinear isotropic model with kinematic hardening, which follows the von-Mises yielding criteria. They also adopt the bilinear elastic-plastic constitutive model. This model requires the definitions of elasticity and plasticity behaviours for the steel materials. The definition of elasticity requires the input of elastic modulus of steels whilst the definition of plasticity requires the input of yield and ultimate strengths and their corresponding plastic strains. This paper adopted the bilinear model, which defines the modulus after yielding equalling to $1 \%$ elastic modulus.

Considering the occurrence of shear fracture to bolts in ECs, continuum damage model (CDM) was adopted for the channels and bolts. Following the methods developed by Yan et al. [25, 26], the CDM was built for C-channels and bolts. The elasticity of ECs and bolts can be defined by the elastic modulus. The definition of CDM includes three main steps, i.e., true stress-strain behaviour of steel, damage initiation, and damage evolution laws.

The true stress-strain $\left(\sigma_{\text {true }}-\varepsilon_{\text {true }}\right)$ curves of C-channels and bolts can be obtained from converting their engineering stress-strain curves following the models in Refs. [25-26] as follows;

$\varepsilon_{\text {true }}=\ln \left(1+\varepsilon_{\text {nom }}\right)$

$\sigma_{\text {true }}=\ln \left(1+\sigma_{\text {nom }}\right)$ where, $\varepsilon_{\text {nom }}$ denotes nominal strain; $\sigma_{\text {nom }}$ is nominal stress.

$\varepsilon_{\text {nom }}$ and $\sigma_{\text {nom }}$ can be obtained from engineering stress-strain curves as recommended in Refs. [25-26]. The determined $\sigma_{\text {true }}-\varepsilon_{\text {true }}$ curves for bolts and Cchannels are given in Fig. 4(b).

The damage initiation strain $\left(\bar{\varepsilon}_{0, p l}\right)$ greatly relates to the stress triaxiality $(\theta)$ of the steels. Their relationships are given by Yan et al. [25-26] as the following;

$\bar{\varepsilon}_{0, \mathrm{pl}}=\varepsilon_{0, \mathrm{pl}} e^{-1.5(\theta-0.333)}$

where, $\bar{\varepsilon}_{0, p l}$ is the uniaxial damage initiation strain can be determined from uniaxial tensile tests on coupons.

Based on the uniaxial stress-strain curves, Fig. 4(c) depicts the damage initiation evolution relationships with $\theta$ for the bolts and $\mathrm{C}$-channels in this numerical study.

The damage coefficient $(D)$ in CDM is an index within 0-1.0 describing the damage from the necking $(D=0)$ to the fracture point $(D=1.0)$ as shown in Fig 4(d). The definition of $D$ ratio at any point between the necking and fracture point follows the model proposed by Yan et al. [25-26] as follows;

$D_{\mathrm{i}}= \begin{cases}1.5\left(1-\sigma_{\mathrm{i}} / \bar{\sigma}_{\mathrm{i}}\right) & i_{\mathrm{D}} \leq i \leq i_{\mathrm{R}} \\ \left(1-D_{\mathrm{R}}\right) \frac{\varepsilon_{\mathrm{i}, \mathrm{pl}}-\varepsilon_{\mathrm{R}, \mathrm{pl}}}{\varepsilon_{\mathrm{F}, \mathrm{pl}}-\varepsilon_{\mathrm{R}, \mathrm{pl}}} & i_{\mathrm{R}} \leq i \leq i_{\mathrm{F}}\end{cases}$

where, $\sigma_{\mathrm{i}}$ is engineering stress at $\mathrm{i} ; \bar{\sigma}_{i}$ is true stress at $\mathrm{i} ; D_{\mathrm{R}}$ is damage ratio at rupture point as shown in Fig. $3(\mathrm{~d}) ; \varepsilon_{\mathrm{i}, \mathrm{pl}}, \varepsilon_{\mathrm{F}, \mathrm{pl}}$ and $\varepsilon_{\mathrm{R}, \mathrm{pl}}$ are plastic strains at points i, fracture, and rupture as illustrated in Fig. 3(d), respectively.

For the CDM definition, the $D_{\mathrm{i}}$ evolution versus equivalent plastic displacement $\left(\bar{u}_{\mathrm{i}, \mathrm{pl}}\right)$ relationship is required, which can be determined using the method in Refs. [25-26]. Finally, Fig. 4(d) plots the determined $D_{\mathrm{i}}-\bar{u}_{\mathrm{i}, \mathrm{s}}$ relationships for bolts and C-channels.

The shear damage criteria was also used in the ABAQUS CDM. The shear damage criteria requires the definitions of shear damage initiation strains ( $\varepsilon_{F \text {,shear }}^{\mathrm{pl}}$ )and evolution laws. Following the method in Refs. [25-26], the $\varepsilon_{F \text {,shear }}^{\mathrm{pl}}$ ratios for the M-6.8, 8.8, 10.9, 12.9 bolts and C-channels equal to 0.12 , $0.095,0.06,0.05$, and 0.118 , respectively. The shear damage evolution follows a displacement mode.

\subsection{Material models of UHPC}

The FEM used the concrete damage plasticity model (CDPM) for the simulation of UHPC slab. The CDPM adopted the yielding function proposed by Lee and Fenves [27] for UHPC. The plasticity parameters of flow potential eccentricity, biaxial-to-uniaxial compressive strength ratio, the dilation angels, and viscosity coefficient of UHPC CDPM were taken as $0.1,1.16,30^{\circ}$, and 0 , respectively. In the CDPM, the uniaxial compression crushing and tensile cracking required to be defined. The tensile and compressive stress-strain behaviours were determined as the following [21];

$$
\sigma_{t}=\left\{\begin{array}{lr}
f_{t} \frac{\varepsilon_{t}}{\varepsilon_{t 0}} & 0 \leq \varepsilon \leq \varepsilon_{t 0} \\
f_{t} & \varepsilon_{t 0}<\varepsilon \leq \varepsilon_{t p} \\
f_{t} \frac{1}{\left(1+w / w_{p}\right)^{p}} & 0<w
\end{array}\right.
$$

$\sigma_{c}=\left\{\begin{array}{cc}f_{c} \frac{k \gamma-\gamma^{2}}{1+(k-2) \gamma} & 0<\varepsilon_{c} \leq \varepsilon_{c 0} \\ f_{c} \frac{\gamma}{2(\gamma-1)^{2}+\gamma} & \varepsilon_{c 0}<\varepsilon_{c} \leq \varepsilon_{u 0}\end{array}\right.$

where, $f_{\mathrm{t}}$ is the UHPC ultimate tensile strength; $\varepsilon_{t 0}$ denotes strain at $f_{\mathrm{t}} ; f_{\mathrm{c}}$ is the UHPC compressive strength; $\varepsilon_{\mathrm{c} 0}$ denotes strain at $f_{\mathrm{c}} ; w_{\mathrm{p}}=0.25 \mathrm{~mm}$, and $p=0.95$; $\gamma=\varepsilon_{\mathrm{c}} / \varepsilon_{\mathrm{c} 0} ; k=E_{\mathrm{c}} / E_{\mathrm{c} 0}$, and equals to 1.19 [21]; $E_{\mathrm{c} 0}$ is the secant modulus at $f_{\mathrm{c}} ; E_{\mathrm{c}}$ denotes initial elastic modulus. 
The developed FEM adopts the continuum element (C3D8R) in ABAQUS to simulate the different components in push-out test specimens except the reinforcement mesh, which used the truss element (T3D2). The C3D8R element in ABAQUS element library is a $3 \mathrm{D}$ element with eight nodes and one integration point. The truss element T3D2, with two nodes and translational degree freedom, was used for the simulation of the reinforcement mesh.

In the explicit solver, the simulation accuracy tends to be influenced by the element size. Thus, a comparative study was performed on the influences of different mesh sizes on the FE simulation results. Fig. 7 compares three types of mesh size studied in the FEM, namely fine, intermediate, and coarse mesh sizes. For the FEM with fine mesh size, the continuum element sizes for the bolt, steel faceplate, and concrete core equal to $2.5 \times 2.5 \times 3 \mathrm{~mm}^{3}, 4.5 \times 4.5 \times 3 \mathrm{~mm}^{3}$, and $7 \times 7 \times 7 \mathrm{~mm}^{3}$, respectively; for the FEM with intermediate mesh size, the continuum element sizes for the bolt, steel faceplate, and concrete core are $2.5 \times 2.5 \times 3 \mathrm{~mm}^{3}, 7 \times 7 \times 3 \mathrm{~mm}^{3}$, and $15 \times 15 \times 15 \mathrm{~mm}^{3}$, respectively; meanwhile, for the FEM with coarse mesh size, the continuum element sizes for the bolt, steel faceplate, and concrete core are $2.5 \times 2.5 \times 3 \mathrm{~mm}^{3}, 8 \times 8 \times 3 \mathrm{~mm}^{3}$, and $20 \times 20 \times 20$ $\mathrm{mm}^{3}$, respectively. Fig. 8 compares the experimental load-slip curves of representative specimens U1A/B and U6A/B with the simulated curves of FEM with different types of mesh sizes. It shows that the FEMs with intermediate $\left(15 \times 15 \times 15 \mathrm{~mm}^{3}\right)$ and fine mesh sizes $\left(7 \times 7 \times 7 \mathrm{~mm}^{3}\right)$ offer more accurate simulation results compared with that of FEM with coarse mesh size $(20 \times 20 \times 20$ $\mathrm{mm}^{3}$ ). Finally, the FEM with fine element size is recommended for the developed FEM for push-out test specimens with UHPC and ECs.

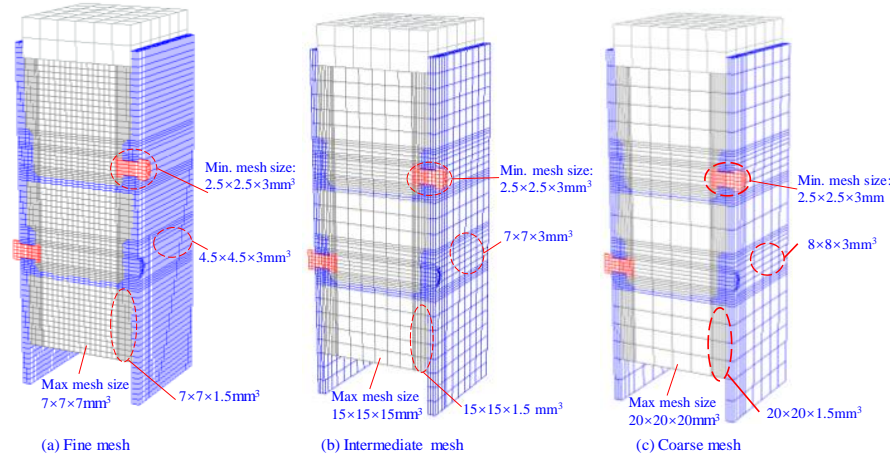

Fig. 7 Different mesh size used in the FEM
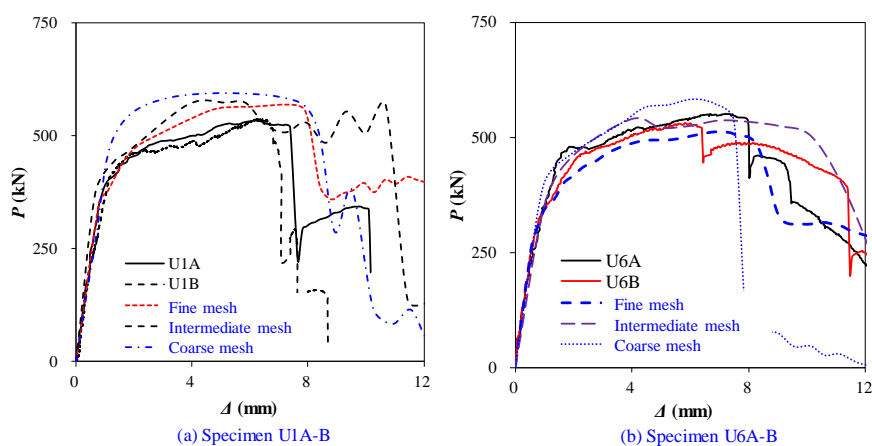

Fig. 8 Different mesh size for the FEM and their influences on FEA

\subsection{Boundary and interactions}

Displacement loading is applied to the top of the loading platen [see Fig. 6 (b)]. Since the symmetric modelling technique was used in the FEM, the symmetric restraints were defined to the mid-plane section, i.e., $\mathrm{Ux}=\mathrm{Ry}=\mathrm{Rz}=0$ ( $\mathrm{U}$ and $\mathrm{R}$ denotes translation and rotation, respectively). The bottom of the specimen was directly put on the bottom rigid base plate. The surface-to-surface (SS) interaction algorithm was adopted for the simulation of faceplate-base interactions. The SS interaction algorithm was also adopted for the simulations on interactions among different components in push-out test specimens, e.g., bolt-faceplate, channel-UHPC core, faceplate-UHPC, and loading platenUHPC core interaction. The SS interaction adopted the "hard contact" and "Coulomb friction model" for the interaction behaviours in the normal and tangential direction at the interaction surface. A friction coefficient of 0.4 was used in the definition of the friction model.

\subsection{Validations}

Fig. 9 compares the numerical failure modes with the experimental failure modes for representative specimens U1A and U6A. It shows that the FEM precisely simulated the failure modes observed from tests, which include the shear off of bolt and shear fracture of the C-channel web as well as their failure sequences. In addition, no failure was found in the UHPC, which implies the shear fracture of the bolts and C-channel web govern the failure of ECs.

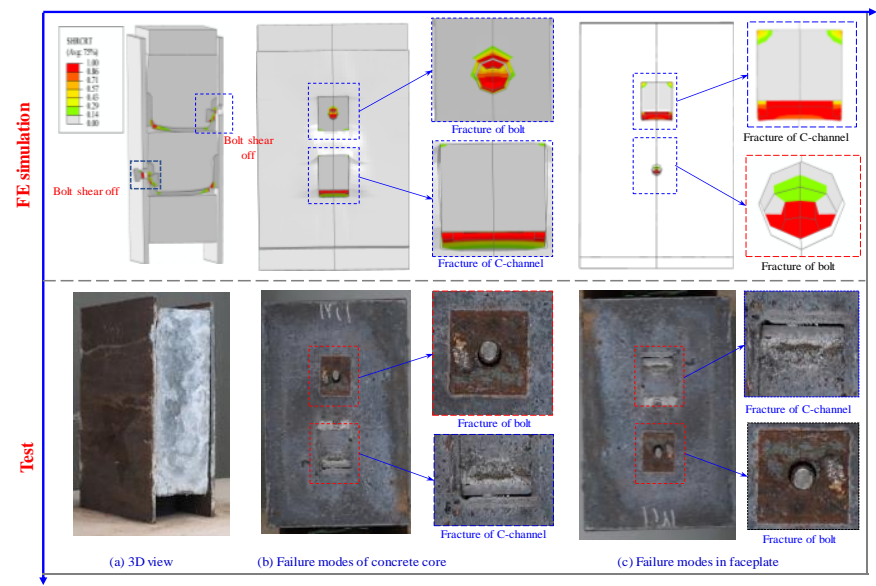

(a) Comparison of specimen U1A

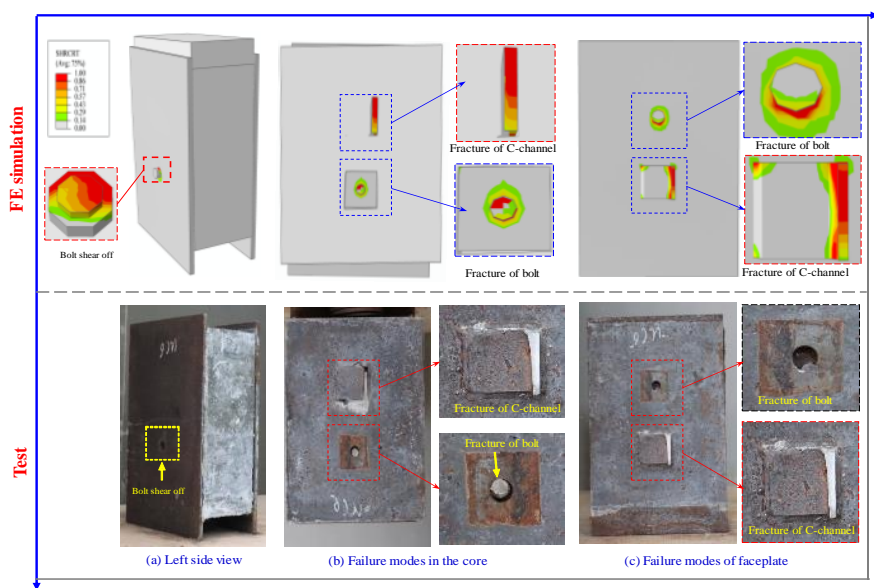

(b) Comparison of specimen U6A

Fig. 9 Comparison of numerical simulatd failure mode with test results
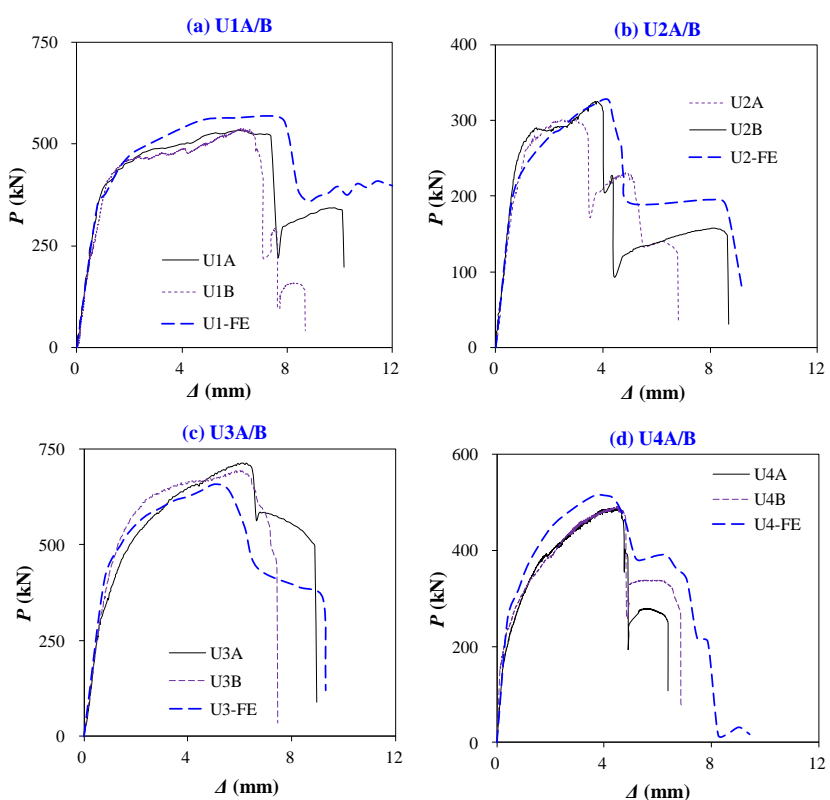

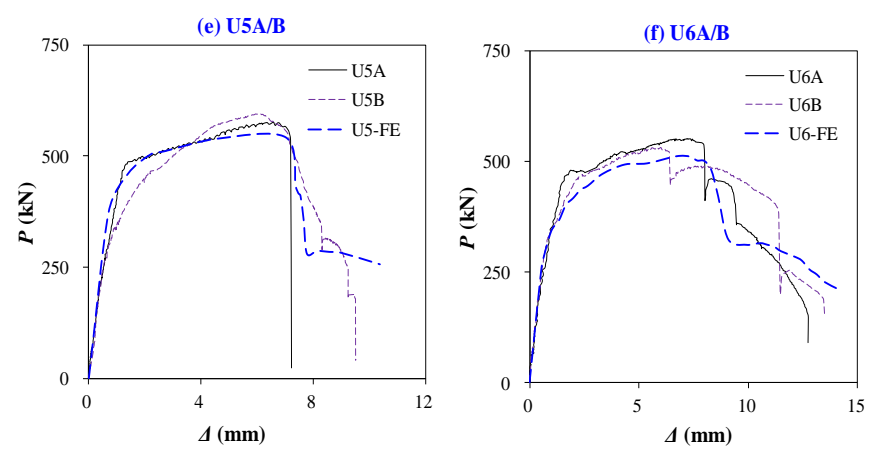

It shows that the developed FEM simulates reasonably well $P$ - $\Delta$ behaviours of ECs embedded in the UHPC slab. Table 1 makes further quantified comparisons of FEM predicted initial stiffness $\left(K_{\mathrm{e}}\right)$, ultimate shear resistance $\left(P_{\mathrm{u}}\right)$, slip $\Delta_{\mathrm{a}}$ at $P_{\mathrm{u}}$, and slip capacity $\left(\Delta_{\mathrm{u}}\right)$ with those results of 12 push-out tests. The $K_{\mathrm{e}}$ is taken as the ratio of $50 \% P_{\mathrm{u}}$ to its corresponding slip at the ascending branch of $P-\Delta$ curve, and the $\Delta_{\mathrm{u}}$ is taken as the slip at $90 \% P_{\mathrm{u}}$ at the recession branch of $P$ - $\triangle$ curve. The comparisons in Table 1 show that the average test-toprediction ratios (and COVs) for the $K_{\mathrm{e}}, P_{\mathrm{u}}, \Delta_{\mathrm{a}}$, and $\Delta_{\mathrm{u}}$ equal to $0.95(0.06)$, 1.01(0.06), 1.03(0.16), and 0.94(0.11), respectively.

These comparisons confirmed that the FEM could reasonably estimate the shear behaviours of ECs in UHPC including failure mode, $P$ - $\triangle$ behaviour, and different strength and slip indexes. Thus, this validated FEM can be further used in the FE parametric study.

Fig. 10 Comparison between the FEM simulated $P$ - $\Delta$ curves with experimental curves.

Table 1

Details and test results of push-out test specimens with EC connectors

\begin{tabular}{|c|c|c|c|c|c|c|c|c|c|c|c|c|c|c|c|}
\hline Item & Web-direction & $h(\mathrm{~mm})$ & $b(\mathrm{~mm})$ & $L_{\mathrm{c}}(\mathrm{mm})$ & $t_{\mathrm{f}}(\mathrm{mm})$ & $t_{\mathrm{w}}(\mathrm{mm})$ & $r(\mathrm{~mm})$ & $r_{1}(\mathrm{~mm})$ & $r_{2}(\mathrm{~mm})$ & $a_{1}(\mathrm{~mm})$ & $a_{2}(\mathrm{~mm})$ & $b_{1}(\mathrm{~mm})$ & $b_{2}(\mathrm{~mm})$ & $f_{\mathrm{c}}(\mathrm{MPa})$ & $E_{\mathrm{c}}(\mathrm{GPa})$ \\
\hline U1A & H-Web & 120 & 53 & 50 & 9 & 5.5 & 14 & 25 & 25 & 100 & 100 & 87 & 120 & 125 & 48.5 \\
\hline U1B & H-Web & 120 & 53 & 50 & 9 & 5.5 & 14 & 25 & 25 & 100 & 100 & 87 & 120 & 125 & 48.5 \\
\hline $\mathrm{U} 2 \mathrm{~A}$ & H-Web & 120 & 53 & 30 & 9 & 5.5 & 14 & 25 & 25 & 110 & 110 & 87 & 120 & 125 & 48.5 \\
\hline U2B & H-Web & 120 & 53 & 30 & 9 & 5.5 & 14 & 25 & 25 & 110 & 110 & 87 & 120 & 125 & 48.5 \\
\hline U3A & H-Web & 120 & 53 & 70 & 9 & 5.5 & 14 & 25 & 25 & 90 & 90 & 87 & 120 & 125 & 48.5 \\
\hline U3B & H-Web & 120 & 53 & 70 & 9 & 5.5 & 14 & 25 & 25 & 90 & 90 & 87 & 120 & 125 & 48.5 \\
\hline U4A & H-Web & 100 & 48 & 50 & 8.5 & 5.3 & 14 & 25 & 25 & 100 & 100 & 82 & 120 & 125 & 48.5 \\
\hline U4B & H-Web & 100 & 48 & 50 & 8.5 & 5.3 & 14 & 25 & 25 & 100 & 100 & 82 & 120 & 125 & 48.5 \\
\hline U5A & H-Web & 140 & 58 & 50 & 9.5 & 6 & 16 & 28 & 25 & 100 & 100 & 92 & 120 & 125 & 48.5 \\
\hline U5B & H-Web & 140 & 58 & 50 & 9.5 & 6 & 16 & 28 & 25 & 100 & 100 & 92 & 120 & 125 & 48.5 \\
\hline U6A & V-Web & 120 & 53 & 50 & 9 & 5.5 & 14 & 25 & 25 & 100 & 100 & 87 & 120 & 125 & 48.5 \\
\hline U6B & V-Web & 120 & 53 & 50 & 9 & 5.5 & 14 & 25 & 25 & 100 & 100 & 87 & 120 & 125 & 48.5 \\
\hline \multicolumn{16}{|c|}{ Table 1 Continued } \\
\hline Item & $\begin{array}{c}K_{\mathrm{e}, \mathrm{T}} \\
\mathrm{kN} / \mathrm{mm}\end{array}$ & $K_{\mathrm{e}, \mathrm{FE}} \mathrm{kN} / \mathrm{mm}$ & $K_{\mathrm{e}, \mathrm{T}}$ & $K_{\mathrm{e}, \mathrm{FE}}$ & $\begin{array}{l}P_{\mathrm{u}, \mathrm{T}} \\
(\mathrm{kN})\end{array}$ & $\begin{array}{l}P_{\mathrm{u}, \mathrm{FE}} \\
(\mathrm{kN})\end{array}$ & $\begin{array}{l}P_{\mathrm{u}, \mathrm{T}} / \\
P_{\mathrm{u}, \mathrm{FE}}\end{array}$ & $\begin{array}{c}\Delta_{\mathrm{a}, \mathrm{T}} \\
(\mathrm{mm})\end{array}$ & $\begin{array}{l}\Delta_{\mathrm{a}, \mathrm{FE}} \\
(\mathrm{mm})\end{array}$ & $\begin{array}{l}\Delta_{\mathrm{a}, \mathrm{T}} / \\
\Delta_{\mathrm{a}, \mathrm{FE}}\end{array}$ & $\begin{array}{c}\Delta \mathrm{u}, \mathrm{T} \\
(\mathrm{mm})\end{array}$ & $\begin{array}{l}\Delta_{\mathrm{u}, \mathrm{FE}} \\
(\mathrm{mm})\end{array}$ & $\begin{array}{l}\Delta_{\mathrm{u}, \mathrm{T} /} \\
\Delta_{\mathrm{u}, \mathrm{FE}}\end{array}$ & $\begin{array}{l}P_{\mathrm{u}, \mathrm{a}} \\
(\mathrm{kN})\end{array}$ & $\begin{array}{l}P_{\mathrm{u}, \mathrm{T}} / \\
P_{\mathrm{u}, \mathrm{a}}\end{array}$ \\
\hline U1A & 431.0 & 445.6 & & 97 & 534.0 & 563.4 & 0.95 & 6.2 & 5.9 & 1.04 & 7.7 & 8.0 & 0.96 & 494 & 1.08 \\
\hline U1B & 439.0 & 445.6 & & 99 & 538.0 & 563.4 & 0.95 & 6.3 & 5.9 & 1.06 & 7.1 & 8.0 & 0.88 & 494 & 1.09 \\
\hline $\mathrm{U} 2 \mathrm{~A}$ & 311.0 & 324.3 & & 96 & 302.0 & 328.2 & 0.92 & 3.1 & 4.2 & 0.74 & 3.5 & 4.6 & 0.77 & 330 & 0.92 \\
\hline U2B & 332.0 & 324.3 & & 02 & 325.0 & 328.2 & 0.99 & 3.7 & 4.2 & 0.89 & 4.0 & 4.6 & 0.88 & 330 & 0.98 \\
\hline U3A & 534.0 & 513.8 & & 04 & 714.0 & 657.8 & 1.09 & 6.1 & 5.1 & 1.21 & 6.6 & 6.2 & 1.07 & 658 & 1.09 \\
\hline U3B & 504.0 & 513.8 & & 98 & 694.0 & 657.8 & 1.06 & 6.1 & 5.1 & 1.21 & 6.7 & 6.2 & 1.08 & 658 & 1.05 \\
\hline U4A & 350.0 & 397.0 & & 88 & 489.0 & 515.0 & 0.95 & 4.8 & 4.0 & 1.20 & 5.1 & 5.2 & 0.99 & 446 & 1.09 \\
\hline U4B & 327.0 & 397.0 & & 82 & 492.0 & 515.0 & 0.96 & 4.9 & 4.0 & 1.22 & 5.2 & 5.2 & 1.00 & 446 & 1.10 \\
\hline U5A & 483.0 & 532.5 & & 91 & 576.0 & 542.1 & 1.06 & 6.6 & 7.0 & 0.94 & 7.2 & 7.4 & 0.98 & 574 & 1.00 \\
\hline U5B & 490.0 & 532.5 & & 92 & 595.0 & 542.1 & 1.10 & 6.1 & 7.0 & 0.87 & 7.2 & 7.4 & 0.98 & 574 & 1.03 \\
\hline U6A & 464.0 & 477.1 & & 97 & 551.0 & 511.0 & 1.08 & 7.2 & 6.7 & 1.07 & 8.0 & 8.6 & 0.93 & 494 & 1.12 \\
\hline U6B & 446.0 & 477.1 & & 93 & 531.0 & 511.0 & 1.04 & 6.0 & 6.7 & 0.90 & 6.4 & 8.6 & 0.74 & 494 & 1.07 \\
\hline Mean & & & & 95 & & & 1.01 & & & 1.03 & & & 0.94 & & 1.05 \\
\hline Cov & & & & 06 & & & 0.06 & & & 0.16 & & & 0.11 & & 0.06 \\
\hline
\end{tabular}

$h$ denotes the depth of the C-channels; $b$ denotes length of the flange of C-channel; $t_{\mathrm{f}}$ denotes the thickness of flange of $\mathrm{C}$-channel; $t_{\mathrm{w}}$ denotes the thickness of web of $\mathrm{C}$-channel; $r, r_{1}, r_{2}, a_{1}$, $a_{2}, b_{1}$, and $b_{2}$ are depicted in Fig. $1 ; f_{\mathrm{c}}$ and $E_{\mathrm{c}}$ denotes compressive strength and modulus of elasticity of UHPC; $K_{\mathrm{e}, \mathrm{T}}, K_{\mathrm{e}, \mathrm{FE}}$ denotes the experimental and numerical initial stiffness of ECs; $P_{\mathrm{u}, \mathrm{T}}, P_{\mathrm{u}, \mathrm{FE}}, P_{\mathrm{u}, \mathrm{a}}$ denotes the experimental and numerical ultimate shear resistance of ECs; $\Delta_{\mathrm{a}, \mathrm{T}}, \Delta_{\mathrm{a}, \mathrm{FE}}$ denotes the experimental and numerical slip at $P_{\mathrm{u}} ; \Delta_{\mathrm{u}, \mathrm{T}}, \Delta_{\mathrm{u}, \mathrm{FE}}$ denotes the experimental and numerical slip capacity.

\section{Numerical parametric studies on shear behaviours of ECs}

\subsection{Introduction on different numerical cases for parametric studies}

With the developed FEM, parametric studies were then carried out to study the key influencing parameters on shear behaviour of ECs in UHPC. Thirty-one cases, namely C1-C31, were prepared in this parametric study. The studied parameters are the gap between the bolt and bolt hole in faceplate (a), diameter $(d)$ and grades $(\mathrm{M})$ of the externally connected bolt, concrete core strength $\left(f_{\mathrm{c}}\right)$, length of C-channel $\left(L_{\mathrm{c}}\right)$, and prestressing ratio of the externally connected bolt $(\rho)$. For the FE push-out studying cases with $d=14 / 18 \mathrm{~mm}$ bolts, different a values of $0,0.5,1.0,1.5,2$, and $3 \mathrm{~mm}$ were prepared, i.e., numerical studying cases $\mathrm{C} 1-\mathrm{C} 6$ or $\mathrm{C} 7-\mathrm{C} 13$. Since the diameter and grade of bolts affects the shear behaviour of ECs, Chinese standard M6.8, 8.8, 10.9, and 12.9 grade of blots were investigated in this study. To investigate the strength of core materials on shear behaviour of ECs, different cases with grade C30, C45, C60, C80, and C120 (UHPC) core were prepared in this study. To study the effect of $L_{\mathrm{c}}$, cases with different $L_{\mathrm{c}}$ values of $25,40,50$, and $75 \mathrm{~mm}$ were also investigated. Finally, 
considering the prestressing force may act on the externally-connected bolts in

investigation. Finally, Table 2 lists the details of these studied 32 cases.

ECs, two cases with a prestressing ratio of 0.2 were prepared for this

Table 2

Details and results of different cases in FE parametric studies

\begin{tabular}{|c|c|c|c|c|c|c|c|c|c|c|c|}
\hline Case & Channel & $L_{\mathrm{c}}(\mathrm{mm})$ & $f_{\mathrm{c}}(\mathrm{MPa})$ & $r(\mathrm{~mm})$ & & $d(\mathrm{~mm})$ & $a(\mathrm{~mm})$ & $\mathrm{M}$ & $\rho$ & $f_{\mathrm{y}}(\mathrm{MPa})$ & $f_{\mathrm{u}}(\mathrm{MPa})$ \\
\hline $\mathrm{C} 1$ & $\mathrm{C} 120$ & 50 & 125.4 & 14 & & 14 & 0 & 8.8 & 0 & 677.6 & 847 \\
\hline $\mathrm{C} 2$ & $\mathrm{C} 120$ & 50 & 125.4 & 15 & & 14 & 0.5 & 8.8 & 0 & 677.6 & 847 \\
\hline $\mathrm{C} 3$ & $\mathrm{C} 120$ & 50 & 125.4 & 16 & & 14 & 1 & 8.8 & 0 & 677.6 & 847 \\
\hline $\mathrm{C} 4$ & $\mathrm{C} 120$ & 50 & 125.4 & 17 & & 14 & 1.5 & 8.8 & 0 & 677.6 & 847 \\
\hline C5 & $\mathrm{C} 120$ & 50 & 125.4 & 18 & & 14 & 2 & 8.8 & 0 & 677.6 & 847 \\
\hline C6 & $\mathrm{C} 120$ & 50 & 125.4 & 20 & & 14 & 3 & 8.8 & 0 & 677.6 & 847 \\
\hline $\mathrm{C} 7$ & $\mathrm{C} 120$ & 50 & 125.4 & 18 & & 18 & 0 & 8.8 & 0 & 677.6 & 847 \\
\hline $\mathrm{C} 8$ & $\mathrm{C} 120$ & 50 & 125.4 & 19 & & 18 & 0.5 & 8.8 & 0 & 677.6 & 847 \\
\hline C9 & $\mathrm{C} 120$ & 50 & 125.4 & 20 & & 18 & 1 & 8.8 & 0 & 677.6 & 847 \\
\hline $\mathrm{C} 10$ & $\mathrm{C} 120$ & 50 & 125.4 & 21 & & 18 & 1.5 & 8.8 & 0 & 677.6 & 847 \\
\hline $\mathrm{C} 11$ & $\mathrm{C} 120$ & 50 & 125.4 & 22 & & 18 & 2 & 8.8 & 0 & 677.6 & 847 \\
\hline $\mathrm{C} 12$ & $\mathrm{C} 120$ & 50 & 125.4 & 24 & & 18 & 3 & 8.8 & 0 & 677.6 & 847 \\
\hline $\mathrm{C} 13$ & $\mathrm{C} 120$ & 50 & 125.4 & 14 & & 14 & 0 & 6.8 & 0 & 468.5 & 585.6 \\
\hline $\mathrm{C} 14$ & $\mathrm{C} 120$ & 50 & 125.4 & 14 & & 14 & 0 & 10.9 & 0 & 984.8 & 1094.2 \\
\hline $\mathrm{C} 15$ & $\mathrm{C} 120$ & 50 & 125.4 & 14 & & 14 & 0 & 12.9 & 0 & 1183 & 1314.4 \\
\hline $\mathrm{C} 16$ & $\mathrm{C} 120$ & 50 & 125.4 & 18 & & 18 & 0 & 6.8 & 0 & 468.5 & 585.6 \\
\hline $\mathrm{C} 17$ & $\mathrm{C} 120$ & 50 & 125.4 & 18 & & 18 & 0 & 10.9 & 0 & 984.8 & 1094.2 \\
\hline C18 & $\mathrm{C} 120$ & 50 & 125.4 & 18 & & 18 & 0 & 12.9 & 0 & 1183 & 1314.4 \\
\hline C19 & $\mathrm{C} 120$ & 50 & 30 & 14 & & 14 & 0 & 8.8 & 0 & 677.6 & 847 \\
\hline $\mathrm{C} 20$ & $\mathrm{C} 120$ & 50 & 45 & 14 & & 14 & 0 & 8.8 & 0 & 677.6 & 847 \\
\hline $\mathrm{C} 21$ & $\mathrm{C} 120$ & 50 & 60 & 14 & & 14 & 0 & 8.8 & 0 & 677.6 & 847 \\
\hline $\mathrm{C} 22$ & C120 & 50 & 80 & 14 & & 14 & 0 & 8.8 & 0 & 677.6 & 847 \\
\hline $\mathrm{C} 23$ & C120 & 50 & 30 & 18 & & 18 & 0 & 8.8 & 0 & 677.6 & 847 \\
\hline $\mathrm{C} 24$ & C120 & 50 & 45 & 18 & & 18 & 0 & 8.8 & 0 & 677.6 & 847 \\
\hline $\mathrm{C} 25$ & $\mathrm{C} 120$ & 50 & 60 & 18 & & 18 & 0 & 8.8 & 0 & 677.6 & 847 \\
\hline $\mathrm{C} 26$ & $\mathrm{C} 120$ & 50 & 80 & 18 & & 18 & 0 & 8.8 & 0 & 677.6 & 847 \\
\hline $\mathrm{C} 27$ & C120 & 75 & 125.4 & 14 & & 14 & 0 & 8.8 & 0 & 677.6 & 847 \\
\hline C28 & $\mathrm{C} 120$ & 40 & 125.4 & 14 & & 14 & 0 & 8.8 & 0 & 677.6 & 847 \\
\hline $\mathrm{C} 29$ & C120 & 25 & 125.4 & 14 & & 14 & 0 & 8.8 & 0 & 677.6 & 847 \\
\hline C30 & $\mathrm{C} 120$ & 50 & 125.4 & 16 & & 14 & 1 & 8.8 & 0.2 & 677.6 & 847 \\
\hline C31 & $\mathrm{C} 120$ & 50 & 125.4 & 20 & & 18 & 1 & 8.8 & 0.2 & 677.6 & 847 \\
\hline \multicolumn{12}{|c|}{ Table 2 Continued } \\
\hline Case & $K_{\mathrm{e}, \mathrm{FE}}(\mathrm{kN} / \mathrm{mm})$ & $P_{\mathrm{u}, \mathrm{FE}}(\mathrm{kN})$ & $\Delta_{\mathrm{a}, \mathrm{FE}}(\mathrm{mm})$ & $\Delta_{\mathrm{u}, \mathrm{FE}}(\mathrm{mm})$ & a/d & $A_{s}\left(\mathrm{~mm}^{2}\right)$ & $P_{\mathrm{c}}(\mathrm{kN})$ & $P_{\mathrm{B}}(\mathrm{kN})$ & $P_{\mathrm{B}} / P_{\mathrm{C}}$ & $P_{\mathrm{u}, \mathrm{a}}(\mathrm{kN})$ & $P_{\mathrm{u}, \mathrm{FE}} / P_{\mathrm{u}, \mathrm{a}}$ \\
\hline $\mathrm{C} 1$ & 811.8 & 597.7 & 2.6 & 3.9 & 0 & 115 & 234.3 & 58.4 & 0.25 & 585.51 & 1.02 \\
\hline $\mathrm{C} 2$ & 589.7 & 616.8 & 3.9 & 5.2 & 0.04 & 115 & 234.3 & 58.4 & 0.25 & 585.51 & 1.05 \\
\hline $\mathrm{C} 3$ & 573.6 & 608.4 & 5.8 & 7.6 & 0.07 & 115 & 234.3 & 58.4 & 0.25 & 585.51 & 1.04 \\
\hline $\mathrm{C} 4$ & 567 & 629.9 & 7.6 & 8.8 & 0.11 & 115 & 234.3 & 58.4 & 0.25 & 585.51 & 1.08 \\
\hline $\mathrm{C} 5$ & 549.2 & 618.8 & 8.8 & 9.7 & 0.14 & 115 & 234.3 & 58.4 & 0.25 & 585.51 & 1.06 \\
\hline C6 & 505.2 & 536.3 & 9.7 & 10.3 & 0.21 & 115 & 234.3 & 58.4 & 0.25 & 585.51 & 0.92 \\
\hline $\mathrm{C} 7$ & 892.5 & 693.6 & 6.2 & 7.9 & 0 & 193 & 234.3 & 98.1 & 0.42 & 664.79 & 1.04 \\
\hline $\mathrm{C} 8$ & 579.8 & 736.7 & 7.5 & 8.7 & 0.03 & 193 & 234.3 & 98.1 & 0.42 & 664.79 & 1.11 \\
\hline C9 & 563.3 & 752.1 & 8.7 & 9.8 & 0.06 & 193 & 234.3 & 98.1 & 0.42 & 664.79 & 1.13 \\
\hline $\mathrm{C} 10$ & 566.5 & 737 & 9.3 & 10.5 & 0.08 & 193 & 234.3 & 98.1 & 0.42 & 664.79 & 1.11 \\
\hline C11 & 590.9 & 725.2 & 12.4 & 13.5 & 0.11 & 193 & 234.3 & 98.1 & 0.42 & 664.79 & 1.09 \\
\hline C12 & 575.9 & 611.4 & 10.7 & 11.4 & 0.17 & 193 & 234.3 & 98.1 & 0.42 & 664.79 & 0.92 \\
\hline C13 & 714.8 & 500.7 & 2.6 & 3.3 & 0 & 115 & 234.3 & 40.4 & 0.17 & 549.43 & 0.91 \\
\hline C14 & 848 & 625.6 & 2.6 & 3.9 & 0 & 115 & 234.3 & 75.5 & 0.32 & 619.63 & 1.01 \\
\hline C15 & 850 & 643.1 & 4.4 & 5.1 & 0 & 115 & 234.3 & 90.7 & 0.39 & 650.01 & 0.99 \\
\hline C16 & 778.5 & 545.6 & 1.9 & 2.6 & 0 & 193 & 234.3 & 67.8 & 0.29 & 604.25 & 0.9 \\
\hline $\mathrm{C} 17$ & 912.9 & 746.1 & 7.3 & 8.9 & 0 & 193 & 234.3 & 126.7 & 0.54 & 722.05 & 1.03 \\
\hline C18 & 912.2 & 824.3 & 11 & 13.1 & 0 & 193 & 234.3 & 152.2 & 0.65 & 773.04 & 1.07 \\
\hline C19 & 558.1 & 413.8 & 6.3 & 7.4 & 0 & 115 & 117.5 & 58.4 & 0.5 & 351.79 & 1.18 \\
\hline $\mathrm{C} 20$ & 646.4 & 465.2 & 5.4 & 6.9 & 0 & 115 & 143.8 & 58.4 & 0.41 & 404.58 & 1.15 \\
\hline $\mathrm{C} 21$ & 710 & 552.1 & 4.4 & 5.6 & 0 & 115 & 166.1 & 58.4 & 0.35 & 449.09 & 1.23 \\
\hline
\end{tabular}




\begin{tabular}{|c|c|c|c|c|c|c|c|c|c|c|c|}
\hline $\mathrm{C} 22$ & 751.4 & 584.3 & 3.5 & 4.5 & 0 & 115 & 191.8 & 58.4 & 0.3 & 500.48 & 1.17 \\
\hline $\mathrm{C} 23$ & 620.9 & 534.4 & 14.4 & 15.3 & 0 & 193 & 117.5 & 98.1 & 0.84 & 431.07 & 1.24 \\
\hline $\mathrm{C} 24$ & 703.6 & 575 & 10.6 & 12.8 & 0 & 193 & 143.8 & 98.1 & 0.68 & 483.86 & 1.19 \\
\hline $\mathrm{C} 25$ & 792.4 & 647.9 & 8.1 & 9.8 & 0 & 193 & 166.1 & 98.1 & 0.59 & 528.37 & 1.23 \\
\hline $\mathrm{C} 26$ & 843 & 669.4 & 6.2 & 8.4 & 0 & 193 & 191.8 & 98.1 & 0.51 & 579.76 & 1.15 \\
\hline $\mathrm{C} 27$ & 1468.4 & 699.9 & 2.4 & 2.9 & 0 & 115 & 351.5 & 58.4 & 0.17 & 819.82 & 0.85 \\
\hline C28 & 684.6 & 465.1 & 2 & 3 & 0 & 115 & 187.4 & 58.4 & 0.31 & 491.78 & 0.95 \\
\hline $\mathrm{C} 29$ & 628.9 & 344.7 & 2.3 & 3 & 0 & 115 & 117.2 & 58.4 & 0.5 & 351.2 & 0.98 \\
\hline C30 & 567.8 & 564.1 & 3.9 & 5.2 & 0 & 115 & 234.3 & 58.4 & 0.25 & 585.51 & 0.96 \\
\hline $\mathrm{C} 31$ & 563.3 & 658.5 & 6.7 & 8.1 & 0 & 193 & 234.3 & 98.1 & 0.42 & 664.79 & 0.99 \\
\hline Mean & & & & & & & & & & & 1.06 \\
\hline Cov & & & & & & & & & & & 0.11 \\
\hline
\end{tabular}

$f_{c}$ denotes the ultimate compressive strength of UHPC; $r$ denotes the diameter of the holes in the channels and steel faceplates; $d$ denotes the diameter of the external bolts; $a$ denotes the gap between the channel and bolt; $M$ denotes the grades of the bolts; $\rho$ denotes the preload ratio of the bolts, which can be defined as $T / A_{s} f_{\mathrm{y}} ; f_{\mathrm{y}}$ and $f_{\mathrm{u}}$ denote the yield and ultimate stress of the bolts; $K_{\mathrm{e}, \mathrm{FE}}$ denotes the numerical initial stiffness of the ECs in parameter studies; $P_{\mathrm{u}, \mathrm{FE}}$ denotes the ultimate strength of ECs in parametric studies; $\Delta_{\mathrm{a}, \mathrm{FE}}$ denotes the slip at $P_{u}$; $\Delta_{\mathrm{u}, \mathrm{FE}}$ denotes the slip capacity of ECs; $A_{s}$ denotes the area of cross section for bolts; $P_{\mathrm{c}}$ denotes shear strength of C-channel in UHPC core; $P_{\mathrm{B}}$ denotes the shear strength of bolts; $P_{\mathrm{u}, \mathrm{a}}$ denotes the analytical ultimate strength of ECs

\subsection{Generalize load-slip behaviour and failure mechanism of ECs in UHPC}

Based on $P-\Delta$ curves of 12 push-out tests and 31 numerical cases, the generalized $P-\triangle$ curve and failure mechanisms are shown in Fig. 11. As reflected in Fig. 11(a), the general $P-\triangle$ curve exhibits three working stages that includes elastic, nonlinear developing, and recession working stages. During the first stage [curve OA in Fig. 11(a)], every component in the push-out specimen behaves elastically until Point A, i.e., stage I end. At point A in Fig. 11(b), the conjunction between the web of $\mathrm{C}$-channel and its flange (welding side rather than the other side with the connected bolts) starts to yield. Thus, in the working stage II, the web of C-channel, connected bolts, flange of C-channel, and faceplates yield as shown in Fig. 11(c), which lead to the nonlinear branch of $P-\triangle$ curve at working stage II. Finally, at the point B in Fig. 11(a), the bottom externally-connected bolt fails in shear fracture [see Fig. 11(c)]; meanwhile, the push-out testing specimen achieves its ultimate shear resistance $\left(P_{\mathrm{u}}\right)$. After point $\mathrm{B}$, the $P-\Delta$ curve enters into its third recession working stage. In stage III, the $P$ - $\triangle$ curve recesses in a zigzag manner with two or three steps. In Fig. 11(a), the load carrying capacity firstly drops to its first step due to fracture of bottom bolt, i.e., curve BC. At the first dropping step end, i.e., point $\mathrm{C}$, shear fracture occurs to the second bolt as shown in Fig. 11(d). After that, the reaction force of specimen drops to the second step, and the $P-\Delta$ curve exhibits a yielding plateau due to the plastic deformation of the C-channel, i.e., curve CD in Fig. 11(a). At Point D, the shear fracture occurs to the web toe of C-channel [see Fig. 11(e)]. In some cases, the webs of two C-channels in ECs failed in a successive way. Thus, the recession $P-\triangle$ curves exhibit two or three steps due to the fracture and plastic deformation of bolts and C-channels.
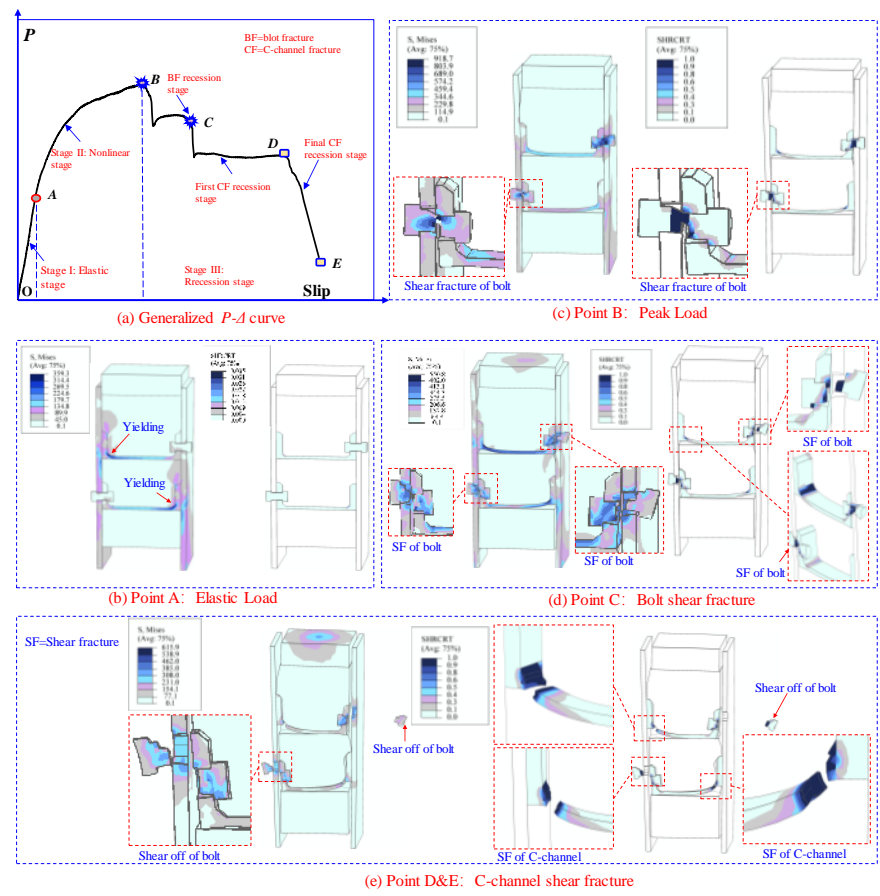

Fig. 11 Generalized load-slip behaviour and failure mechnism of ECs in UHPC

\subsection{Effect of gap between bolt hole and bolt (a)}

Fig. 12(a) and (b) plots the effects of a on $P$ - $\triangle$ curves of push-out numerical cases with $d=14$ and $18 \mathrm{~mm}$, respectively. Fig. 13(a)-(b) illustrates the effect of $a$ on strength and slip capacity indexes of $P_{\mathrm{u}}, K_{\mathrm{e}}, \Delta_{\mathrm{a}}$, and $\Delta_{\mathrm{u}}$. These figures show that;

(1) As the $a$ value increases from 0 to $0.5,1.0 .1 .5,2.0$, and $3 \mathrm{~mm}$, the shear stiffness of ECs with $d=14 \mathrm{~mm}$ bolts was reduced by $18 \%, 20 \%, 21 \%, 23 \%$, and $29 \%$, respectively; meanwhile, these reductions for ECs with $d=18 \mathrm{~mm}$ bolts equal to $35 \%, 37 \%, 37 \%, 34 \%$, and $36 \%$, respectively. This is due to that the bolt-faceplate gap (a) requires the additional slip before the full touch of faceplates to the externally-connected bolts, which compromises the shear stiffness of ECs.

(2) The increasing a value from 0 to $2 \mathrm{~mm}$ exhibits marginal influences on the $P_{\mathrm{u}}$ of ECs, but the increasing a value from 2 to $3 \mathrm{~mm}$ significantly reduces the $P_{\mathrm{u}}$ of ECs. As the $a$ value increases from 0 to $0.5,1.0 .1 .5,2.0$, and $3 \mathrm{~mm}$, the $P_{\mathrm{u}}$ of ECs with $d=14 \mathrm{~mm}$ bolts was slightly reduced by $5 \%, 4 \%, 4 \%, 4 \%$, and $14 \%$, respectively; meanwhile, the $P_{\mathrm{u}}$ of ECs with $d=18 \mathrm{~mm}$ bolts was reduced by $-6 \%,-8 \%,-6 \%,-5 \%$, and $12 \%$, respectively (negative increments means increment). This is because that setting the bolt-hole gap could be tolerated by the ductile C-channel as $a$ is less than $2.0 \mathrm{~mm}$. However, as the $a$ is beyond $2.0 \mathrm{~mm}$, the shear resistance of the C-channel tends to be compromised. Thus, from this point of view, the $a$ value needs to be controlled within $2 \mathrm{~mm}$ for the developed ECs.

(3) Increasing the $a$ value in ECs significantly improves the slip capacity of ECs with both $d=14 \mathrm{~mm}$ and $18 \mathrm{~mm}$ bolts in UHPC. As the $a$ value increases from 0 to $0.5,1.0 .1 .5,2.0$, and $3 \mathrm{~mm}$, the $\Delta_{\mathrm{u}}$ (or $\Delta_{\mathrm{a}}$ ) of ECs with $d=14 \mathrm{~mm}$ bolts is increased by $127 \%(114 \%), 172 \%(161 \%), 215 \%(248 \%), 261 \%(273 \%)$, and $336 \%(333 \%)$, respectively; meanwhile, the the $\Delta_{\mathrm{u}}\left(\right.$ or $\Delta_{\mathrm{a}}$ ) of ECs with $d=18 \mathrm{~mm}$ bolts is increased by $10 \%(21 \%), 25 \%(40 \%), 33 \%(50 \%), 52 \%(85 \%)$, and $68 \%(106 \%)$, respectively. The improvements on the ECs with bolts in smaller diameter is more significant. This is because that the shear deformation capacity of the bolts at their ultimate shear resistance is smaller than that of the $\mathrm{C}$-channel. The reserving bolt-faceplate hole gap could delay the shear deformation of bolts that could avoid the bolts fail prior to the development of full plastic deformation of bolts.

The above findings reveal that reserving the bolt-faceplate hole gap within $2 \mathrm{~mm}$ does not harm the shear resistance of ECs in UHPC, but greatly improves the slip capacity of ECs. However, as the gap $a$ is beyond $3 \mathrm{~mm}$, the shear capacity of ECs will be affected even though the slip capacity is still improved. Moreover, reserving the bolt-faceplate hole gap will be beneficial for the installation of the ECs that could tolerate the fabrication errors.
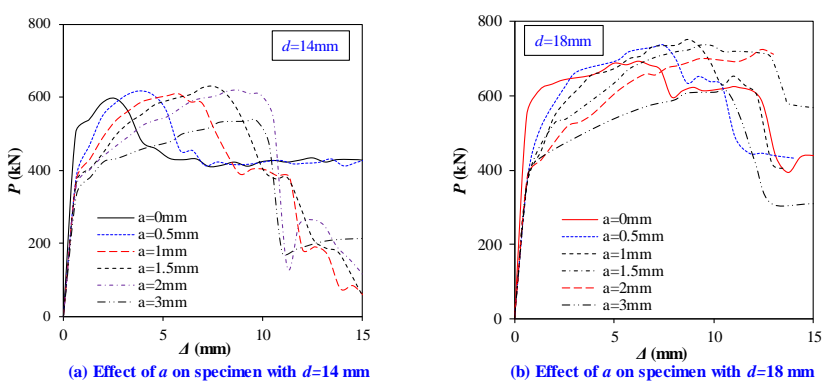

Fig. 12 Effect of $a$ on load-slip behaviours of ECs 

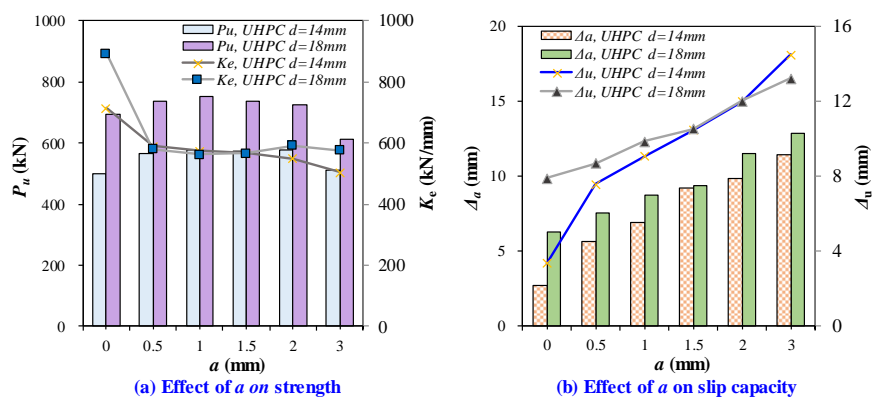

Fig. 13 Effects of gap between bolt and bolt holes $(a)$

\subsection{Effect of diameter of grades $(M)$ and diameter (d) of bolts}

Fig. 14(a)-(b) depicts the effects of $M$ on $P$ - $\triangle$ curves of push-out numerical cases with $d=14$ and $18 \mathrm{~mm}$, respectively. Fig. 15(a)-(b) plots the influences of $\mathrm{M}$ on the strength and slip capacity, i.e., $P_{\mathrm{u}}, K_{\mathrm{e}}, \Delta_{\mathrm{a}}$, and $\Delta_{\mathrm{u}}$. These figures show that increasing the $M$ of externally-connected bolts generally improves both shear resistance and ductility of ECs with UHPC. As the grade of the bolts increases from M6.8 to M8.8, M10.9, and M12.9, the $P_{\mathrm{u}}$ (or $K_{\mathrm{e}}$ ) of ECs with $d=14 \mathrm{~mm}$ bolts was increased by $19 \%(14 \%), 25 \%(19 \%)$, and $28 \%(19 \%)$, respectively; meanwhile, the $P_{\mathrm{u}}$ (or $K_{\mathrm{e}}$ ) of ECs with $d=18 \mathrm{~mm}$ bolts was increased by $27 \%(15 \%), 37 \%(17 \%)$, and $51 \%(17 \%)$, respectively; the $\Delta_{\mathrm{u}}$ (or $\left.\Delta_{\mathrm{a}}\right)$ of ECs with $d=14 \mathrm{~mm}$ bolts was increased by $19 \%(-2 \%), 17 \%(-2 \%)$, and $54 \%(69 \%)$, respectively; and the $\Delta_{\mathrm{u}}$ (or $\Delta_{\mathrm{a}}$ ) of ECs with $d=18 \mathrm{~mm}$ bolts was increased by $205 \%(221 \%), 246 \%(278 \%)$, and $408 \%(469 \%)$, respectively. Moreover, it can be also found that the improvements on strength and ductility for ECs with larger diameter bolts are more significant. In addition, the ECs was gradually changed from the brittle to ductile connectors as the $\mathrm{M}$ of externallyconnected bolts increases. These improvements received from the increasing the grade of bolts is due to the increased shear strength of bolts $\left(P_{\mathrm{B}}\right)$. Since the Cchannel is more ductile compared with the bolts, the $P_{\mathrm{B}}$ to shear resistance of the C-channel $\left(P_{\mathrm{C}}\right)$ are required to be well controlled to make sure the full utilization of the plastic deformation of C-channels. The $P_{\mathrm{B}}$ and $P_{\mathrm{C}}$ can be determined as the following:

$P_{B}=\sigma_{u} A_{s b}$

$P_{C}=0.25 \alpha f_{c} L_{c} h+\frac{t_{w}^{2} L_{c}}{0.52 h} f_{u}$

where, $t_{\mathrm{w}}$ is the web thickness; $L_{\mathrm{c}}$ denotes the channel length; $f_{\mathrm{c}}$ is the UHPC compressive strength; $f_{\mathrm{u}}$ is the ultimate strength of $\mathrm{C}$-channel.

Thus, the $P_{\mathrm{B}}, P_{\mathrm{C}}$, and the $P_{\mathrm{B}} / P_{\mathrm{C}}$ ratios for each numerical case are calculated in Table 2. It can be found that as the grade of the bolts increases from M6.8 to M8.8, M10.9, and M12.9, the $P_{\mathrm{B}} / P_{\mathrm{C}}$ ratio of ECs with $d=14 \mathrm{~mm}$ bolts is increased from 0.17 to $0.25,0.32$, and 0.39 , respectively; meanwhile, the $P_{\mathrm{B}} / P_{\mathrm{C}}$ ratio of ECs with $d=14 \mathrm{~mm}$ bolts is increased from 0.25 to $0.42,0.54$, and 0.65 , respectively. This explains the improvements on strength and deformation capacity of ECs through using higher grade bolts. Moreover, this also explains the larger improvements on the shear resistance and slip capacity of ECs with $d=18 \mathrm{~mm}$ bolts than those of ECs with $d=14 \mathrm{~mm}$ bolts since the $P_{\mathrm{B}} / P_{\mathrm{C}}$ ratios for ECs with $d=18 \mathrm{~mm}$ bolts are much larger than those with $d=14 \mathrm{~mm}$ bolts. In addition, one interesting finding in Fig. 14 is that as the $P_{\mathrm{B}} / P_{\mathrm{C}}$ ratio is larger than 0.5 the slip capacity of the ECs with UHPC could meet the minimum required slip capacity of $6 \mathrm{~mm}$ for the ductile connectors as specified in Eurocode 4 [28].

Thus, increasing the diameter $(d)$ of bolts in ECs also improves the shear strength and slip capacity of ECs [see Fig. 15(c)-(d)]. With the increase of $d$ value of bolts from 14 to $18 \mathrm{~mm}$, the Ke is slightly increased by $10 \%, 8 \%$, and $7 \%$ for ECs with grade M8.8, M10.9, and M12.9 bolts, respectively; the $K_{\mathrm{e}}$ is significantly increased by $16 \%, 19 \%$, and $28 \%$ for ECs with grade M8.8, M10.9, and M12.9 bolts, respectively; and the $\Delta_{\mathrm{u}}$ (or $\Delta_{\mathrm{a}}$ ) of ECs are dramatically increased by $100 \%(140 \%), 131 \%(184 \%)$, and 155\%(148\%) for ECs with grade M8.8, M10.9, and M12.9 bolts, respectively. The reason is similar to that of increasing $\mathrm{M}$ of bolts, which increased the $P_{\mathrm{B}} / P_{\mathrm{C}}$ ratios of ECs.

Thus, the $P_{\mathrm{B}} / P_{\mathrm{C}}$ ratios of ECs required to be well controlled that make sure the full use of the plastic deformation of C-channels, i.e., the $P_{\mathrm{B}}$ should match the $P_{\mathrm{C}}$ to guarantee a ductile connector or the shear fracture of the $\mathrm{C}$-channel should be prior to the shear fracture of bolts. This can be realized through adjusting the $P_{\mathrm{B}} / P_{\mathrm{C}}$ ratio.
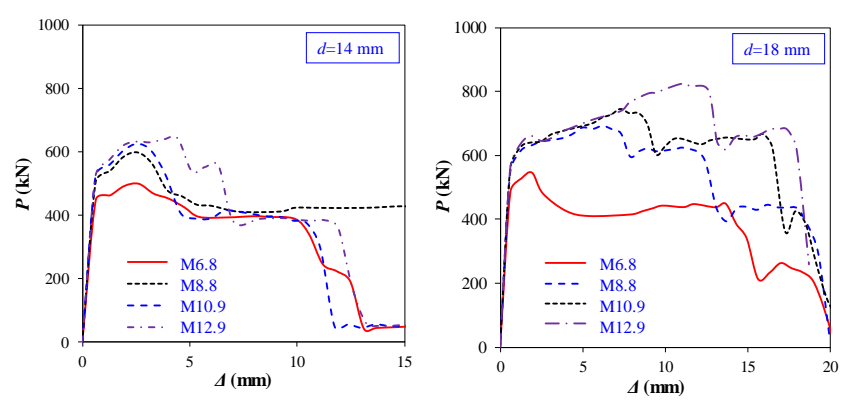

(a) Effect of $M$ on specimen with $d=14 \mathrm{~mm}$

Fig. 14 Effect of $M$ and $d$ on load-slip behaviours of ECs

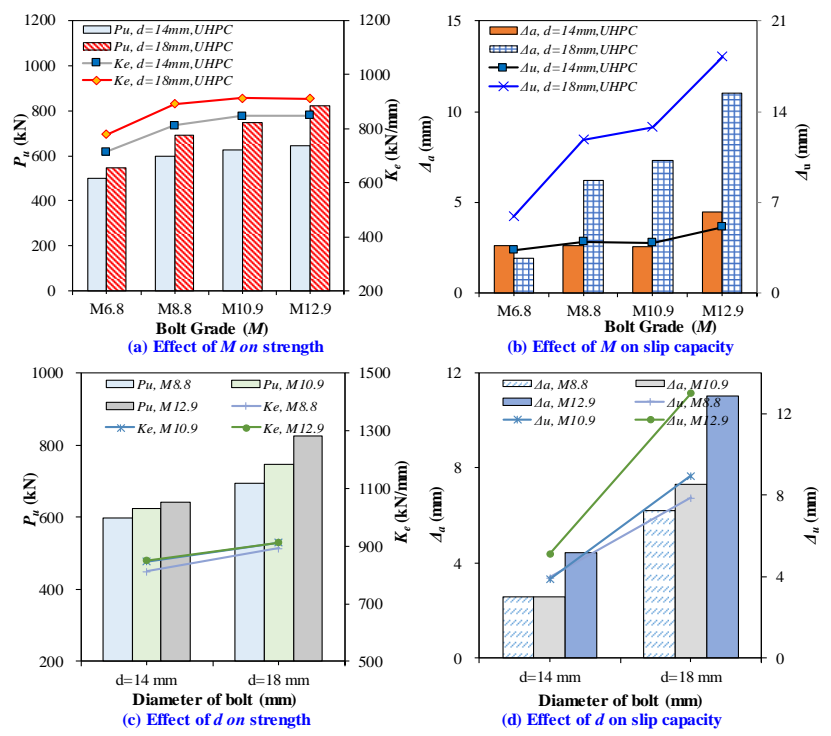

Fig. 15 Effect of $M$ and $d$ on load-slip behaviours of ECs

\subsection{Effect of concrete strength $\left(f_{\mathrm{c}}\right)$}

Fig. 16(a) and (b) plots the effects of $f_{\mathrm{c}}$ on $P$ - $\triangle$ curves of push-out numerical cases with $d=14$ and $18 \mathrm{~mm}$, respectively. Fig. 17(a) and (b) plots the influences of $f_{\mathrm{c}}$ on the strength and slip capacity, i.e., $P_{\mathrm{u}}, K_{\mathrm{e}}, \Delta_{\mathrm{a}}$, and $\Delta_{\mathrm{u}}$. These figures show that increasing the grade of concrete from $\mathrm{C} 30$ to $\mathrm{C} 120$ (UHPC) improves the shear resistance but reduces the slip capacity of ECs. As the grade of concrete increases from C30 to C45, C60, C80, and C120(UHPC), the $P_{\mathrm{u}}\left(\right.$ or $\left.K_{\mathrm{e}}\right)$ of ECs with $d=14 \mathrm{~mm}$ bolts was increased by $12 \%(16 \%), 33 \%(27 \%), 41 \%(35 \%)$, and $44 \%(45 \%)$, respectively; meanwhile, the $P_{\mathrm{u}}$ ( or $K_{\mathrm{e}}$ ) of ECs with $d=18 \mathrm{~mm}$ bolts was increased by $8 \%(13 \%), 21 \%(28 \%), 25 \%(36 \%)$, and $30 \%(44 \%)$, respectively; however, the $\Delta_{\mathrm{u}}$ ( or $\Delta_{\mathrm{a}}$ ) of ECs with $d=14 \mathrm{~mm}$ bolts was reduced by $6 \%(15 \%), 24 \%(31 \%), 39 \%(45 \%)$, and $477 \%(59 \%)$, respectively; and the $\Delta_{\mathrm{u}}$ (or $\Delta_{\mathrm{a}}$ ) of ECs with $d=18 \mathrm{~mm}$ bolts was reduced by $16 \%(26 \%), 36 \%(44 \%)$, $45 \%(57 \%)$, and $49 \%(57 \%)$, respectively. This is because increasing the core strength increases the shear resistance of C-channel, but reduces the $P_{\mathrm{B}} / P_{\mathrm{C}}$ ratios of ECs that results in reduced slip capacity of the ECs. As the grade of concrete core increases from $\mathrm{C} 30$ to $\mathrm{C} 45, \mathrm{C} 60, \mathrm{C} 80$, and $\mathrm{C} 120$ (UHPC), the $P_{\mathrm{B}} / P_{\mathrm{C}}$ ratio of ECs with $d=14$ (or 18) mm bolts are reduced from $0.50(0.84)$ to $0.41(0.68)$, $0.35(0.59), 0.30(0.51)$, and $0.25(0.42)$, respectively. This implies using high strength concrete core requires using higher strength bolts to match the increased shear resistance of C-channel in the ECs to make sure the ductility of ECs, which is realized through increasing the $P_{\mathrm{B}} / P_{\mathrm{C}}$ ratio of ECs.
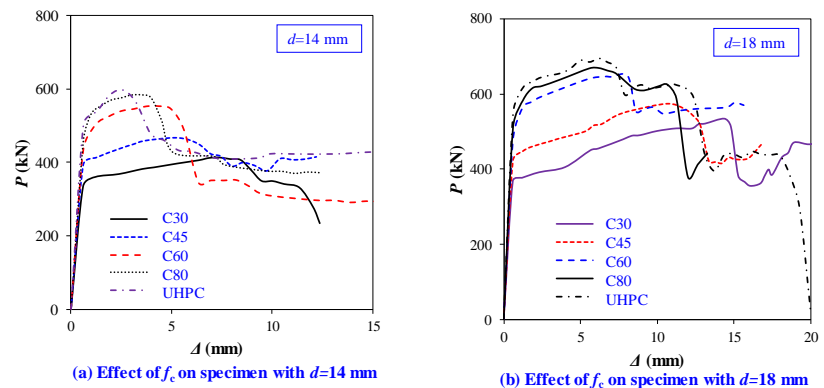

Fig. 16 Effect of $f_{\mathrm{c}}$ on load-slip behaviours of ECs 


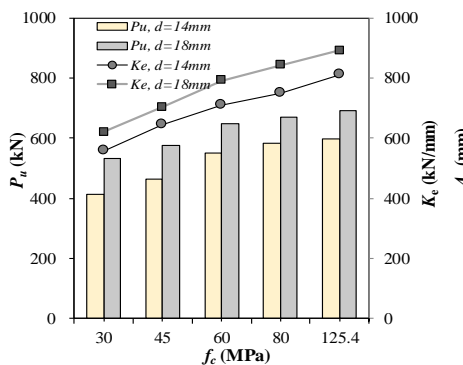

(a) Effect of $f_{\mathrm{c}}$ on strength

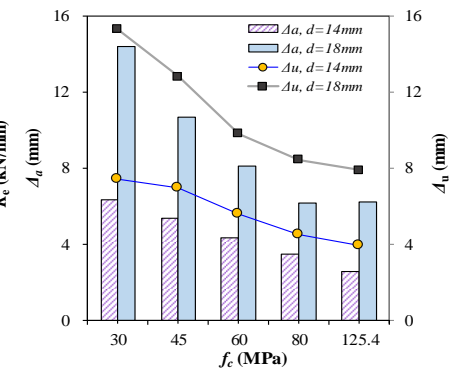

(b) Effect of $f_{\mathrm{c}}$ on slip capacity
Fig. 17 Effect of strength of concrete on strength and ductility index of Ecs

\subsection{Effect of length of C-channel $\left(L_{\mathrm{c}}\right)$}

Fig. 18(a) depicts the effects of $L_{\mathrm{c}}$ on $P-\triangle$ curves of push-out numerical cases. Fig. 19(a)-(b) illustrates the influences of $L_{\mathrm{c}}$ on the strength and slip capacity. These figures show that increasing the $L_{\mathrm{c}}$ from $25 \mathrm{~mm}$ to 40,50 , and $75 \mathrm{~mm}$ improvs the $P_{\mathrm{u}}$ (or $K_{\mathrm{e}}$ ) of ECs by $35 \%(9 \%), 45 \%(14 \%)$, and $103 \%(134 \%)$, respectively; meanwhile, the $\Delta_{\mathrm{u}}$ (or $\Delta_{\mathrm{a}}$ ) of ECs is slightly reduced by $1 \%(14 \%),-10 \%(-16 \%)$, and $6 \%(-6 \%)$, respectively (negative value means increase). The increasing length of $L_{\mathrm{c}}$ increases the shear resistance of Cchannel and thus increased the shear resistance of ECs. However, the ECs with $L_{\mathrm{c}}$ value of $50 \mathrm{~mm}$ offers the best slip capacity. Thus, in the developed ECs, the optimized $L_{\mathrm{c}}$ value of $50 \mathrm{~mm}$ is recommended for ECs with UHPC.

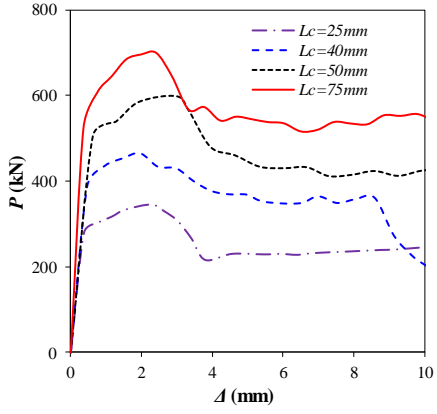

(a) Effect of $L_{c}$

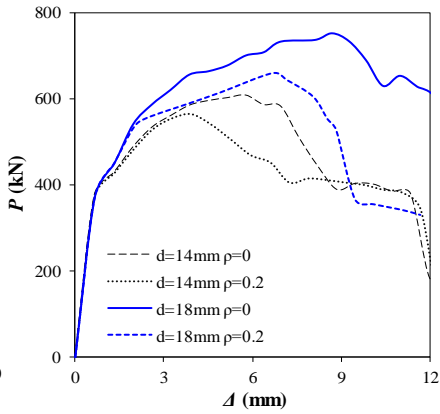

(b) Effect of $\rho$
Fig. 18 Effect of $L_{\mathrm{c}}$ and $\rho$ on load-slip behaviours of ECs

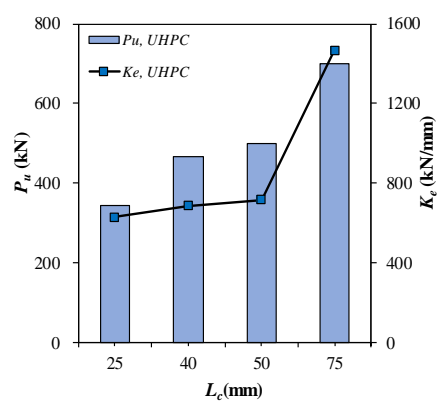

(a) Effect of $L_{\mathrm{c}}$ on strength

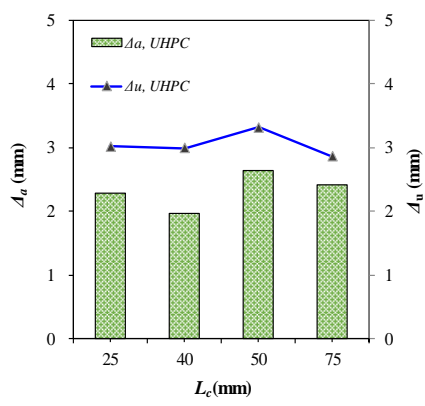

(b) Effect of $L_{\mathrm{c}}$ on slip capacity
Fig. 19 Effect of length of C-channel $\left(L_{\mathrm{c}}\right)$

\subsection{Effect of prestressing ratio of bolt ( $\rho)$}

The prestressing force is usually applied to the bolt during the installation of ECs. This study designed two cases with $\rho=0.2\left(\rho=T / \sigma_{\mathrm{y}} A_{\mathrm{sb}}\right)$. Fig. 18(b) plots the effects of $\rho$ on $P$ - $\Delta$ curves of push-out numerical cases. Fig. 20(a) and (b) shows the influences of $\rho$ on the strength and slip capacity. These figures reflect that increasing the prestressing force on the bolts reduces both the shear resistance and ductility of ECs. Applying $\rho=0.2$ prestressing force reduces the $P_{\mathrm{u}}$ and $\Delta_{\mathrm{u}}\left(\right.$ or $\Delta_{\mathrm{a}}$ ) of ECs with $d=14 \mathrm{~mm}$ bolts by $7 \%$ and $31 \%(32 \%)$, respectively meanwhile, applying $\rho=0.2$ prestressing force reduces the $P_{\mathrm{u}}$ and $\Delta_{\mathrm{u}}\left(\right.$ or $\Delta_{\mathrm{a}}$ ) of ECs with $d=18 \mathrm{~mm}$ bolts by $13 \%$ and $18 \%(23 \%)$, respectively. Thus, controlling the prestressing force acting on the bolts in ECs within 0.2 is still important on maintaining the shear performance of ECs in UHPC.
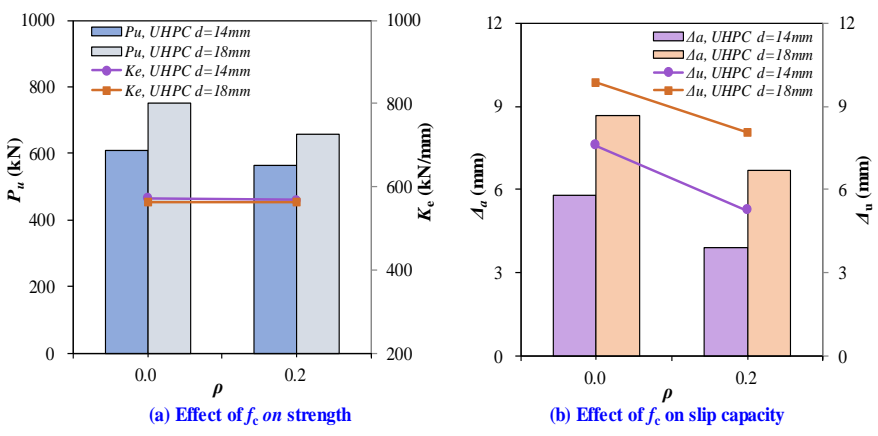

Fig. 20 Effect of length of C-channel $\left(L_{\mathrm{c}}\right)$

\section{Analytical models on ultimate shear resistance and shear-slip} behaviours of ECs with UHPC

\subsection{Introduction on different numerical cases for parametric studies}

Based on the recommended models by Yan et al. [29], the $P_{\mathrm{u}}$ of ECs with UHPC is calculated as follows:

$P_{\mathrm{u}}=P_{\mathrm{c}}+P_{\mathrm{B}}$

$P_{\mathrm{B}}=\sigma_{\mathrm{u}} A_{\mathrm{sb}} ; P_{\mathrm{C}}=0.25 \alpha f_{\mathrm{c}} L_{\mathrm{c}} h+\frac{t_{\mathrm{w}}^{2} L_{\mathrm{c}}}{0.52 h} f_{\mathrm{u}}$

where, $t_{\mathrm{w}}$ is the web thickness; $L_{\mathrm{c}}$ is the channel length; $f_{\mathrm{c}}$ is the UHPC compressive strength; $f_{\mathrm{u}}$ is the ultimate strength of C-channel.

Based on the reported generalized $P / P_{\mathrm{u}}-\Delta$ curves of 12 tests and 31 numerical simulations, this paper developed an empirical equation to describe the $P / P_{\mathrm{u}}-\Delta$ curves of ECs with UHPC by the regression analysis method. Moreover, the developed analytical model also considers the influence of the bolt-hole gap ( $a$ ) as the following:

$\frac{P}{P_{\mathrm{u}}}=\frac{\left(6.23 \frac{a}{d}+0.13\right)^{-1} \Delta}{1+\left[\left(6.23 \frac{a}{d}+0.13\right)^{-1}-0.1\right] \Delta}$

where, $a$ is the bolt-hole gap and less than $2 \mathrm{~mm}$; $d$ is the bolt diameter; $\Delta$ is the slip, in $\mathrm{mm}$.

For the 12 push-out tests with the a/d of $1 / 28$, Eqn. (11) is changed as the following:

$\frac{P}{P_{u}}=\frac{2.26 \Delta}{1+2.16 \Delta}$

\subsection{Validations}

The predicted ultimate shear resistances of numerical cases and tests are given in Table 1. Fig. 21 compared the analytical predictions of $P_{\mathrm{u}}$ with those of 31 numerical analysis and 12 test results. These table and figure show that the average test/FE-to-prediction ratio and COV (coefficient of variation) for these 43 cases equal to 1.06 and 0.09 , respectively. The developed analytical model offers a $6 \%$ average underestimation on $P_{\mathrm{u}}$ of ECs in UHPC. Fig. 22 compared the test/FE generalized load-slip curves with those predicted curves by Eqn. (11). It shows that the proposed equations, i.e., Eqn. (11) offer reasonable simulations on generalized $P-\Delta$ behaviours of ECs in UHPC. Moreover, the influences of different bolt-hole gap were considered in the developed models. 


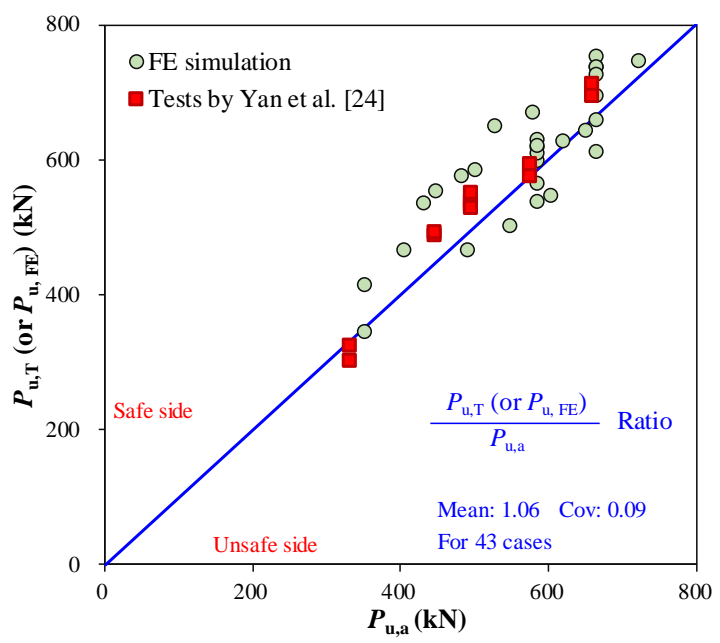

Fig. 21 Comparisons of predicted ultimate shear resistances with test/FE results
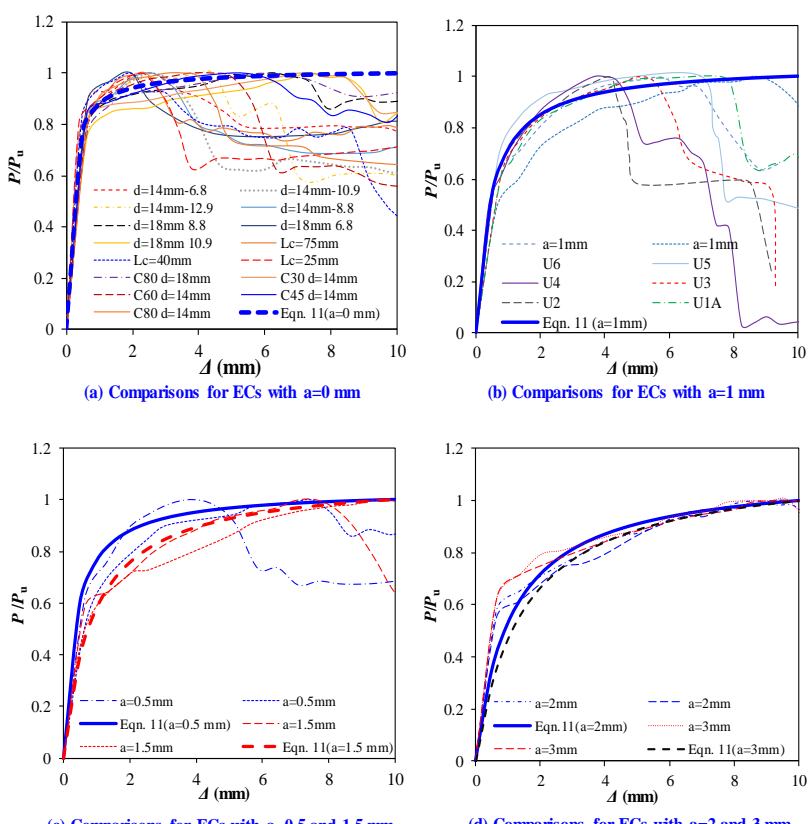

(c) Comparisons for ECs with $\mathrm{a}=0.5$ and $1.5 \mathrm{~mm}$

(d) Comparisons for ECs with $\mathrm{a}=2$ and $3 \mathrm{~mm}$

Fig. 22 Validations of analytical predicted gerneralzied load-slip curves against test and numerical ones

\subsection{Discussions and recommendations on design of ECs in UHPC}

To tolerate the fabrication and installation errors of different components in ECs, the bolt-hole gap (a) is recommended for the SUSSS-ECs. The recommended bolt-hole gap $(a)$ is less than $2 \mathrm{~mm}$, which showed improved slip capacity and no influence on $P_{\mathrm{u}}$ of ECs with UHPC.

For design on SUSSS-ECs, the $P_{\mathrm{B}} / P_{\mathrm{C}}$ ratio of the ECs requires to be increased to make sure the slip capacity of ECs. From the load-slip curves in Fig. 12, the $P_{\mathrm{B}} / P_{\mathrm{C}}$ ratio is recommended to be larger than 0.5 .

\section{Conclusions}

This paper firstly developed a 3D nonlinear FEM for ECs with UHPC. The developed FEM was validated by 12 push-out tests on ECs with UHPC. Followed in-depth parametric studies were performed to study the key influencing parameters on shear behaviours of ECs with UHPC. Analytical studies were also performed on ultimate shear resistance and shear-slip behaviours of ECs with UHPC. These studies support the following conclusions:

(1) The proposed FEM could simulate well shear behaviours of ECs as well as the shear fracture of C-channel and bolts using the CDM. The validations of FE simulations against 12 push-out tests show that the average prediction errors for strength and ductility indexes of $P_{\mathrm{u}}, K_{\mathrm{e}}, \Delta_{\mathrm{u}}$, and $\Delta_{\mathrm{a}}$ are $1 \%, 5 \%, 3 \%$, and $6 \%$, respectively.

(2) Under interfacial shear force, the ECs with UHPC firstly yielded at the toe of C-channel web, and then yielded at the bolt. At the ultimate shear load point, shear fracture occurred to the bolt. The recession branch of the shear-slip curves exhibited a zigzag way with several steps due to the successive shear fracture of bolts and C-channels.

(3) Reserving the bolt-hole gap (a) less than $2 \mathrm{~mm}$ did not reduce the ultimate shear resistance of ECs with UHPC, but greatly improved their slip capacities. As the a is beyond $2 \mathrm{~mm}$, the ultimate shear resistance of ECs was significantly reduced.

(4) Increasing the grades and diameter of externally-connected bolts improves the shear behaviour of ECs with UHPC through increasing the $P_{\mathrm{B}} / P_{\mathrm{C}}$ ratio. The $P_{\mathrm{B}} / P_{\mathrm{C}}$ ratio is recommended to be larger than 0.5 for ECs with UHPC to make a ductile connector.

(5) The increasing core strength improved the C-channel shear resistance, but reduced the $P_{\mathrm{B}} / P_{\mathrm{C}}$ ratio that resulted in reduced ductility of ECs. Increasing the core strength required using stronger externally-connected bolt to maintain the slip capacity through increasing the $P_{\mathrm{B}} / P_{\mathrm{C}}$ ratio of ECs.

(6) The length of C-channels in ECs at $50 \mathrm{~mm}$ offered the best slip capacity, which is a recommended optimized dimension for the ECs with UHPC.

(7) Prestressing force acting on the externally-connected bolts reduces both the shear resistance and ductility of ECs with UHPC. Controlling the prestressing force acting on the bolts in ECs within 0.2 is still important on maintaining the shear performance of ECs in UHPC.

(8) Analytical models incorporating the influences of bolt-hole gaps were developed to describe the $P / P_{\mathrm{u}}-\Delta$ curves and $P_{\mathrm{u}}$ of ECs with UHPC. Validations against the 12 push-out tests and 31 FEM analysis results proved that these developed analytical models predicted well shear behaviour of ECs with UHPC.

\section{Nomenclature}

$A_{\mathrm{sb}} \quad$ Area of cross section for bolt

$B \quad$ Width of flange of C-channel

$D$ Damage coefficient

$D_{\mathrm{R}} \quad$ Damage ratio at rupture point

$E_{\mathrm{c} 0}$ the secant modulus at $f_{\mathrm{c}}$

$E_{\mathrm{c}}$ denotes initial elastic modulus of concrete

$E_{\mathrm{s}} \quad$ Elastic modulus of steel

$K_{e, T} \quad$ Experimental initial stiffness of ECs

$K_{e, F E} \quad$ Numerical initial stiffness of ECs

$L_{c} \quad$ Length of the flange of C-channel

$M \quad$ Grade of externally connected bolt

$P \quad$ Load

$P_{\mathrm{B}} \quad$ Shear strength of bolt

$P_{\mathrm{C}} \quad$ Shear strength of C-channel in UHPC core

$P_{\mathrm{u}} \quad$ Ultimate shear resistance

$P_{\mathrm{u}, \mathrm{T}} \quad$ Ultimate shear resistance of specimen in the test

$P_{\mathrm{u}, \mathrm{FE}} \quad$ Ultimate shear resistance of specimen in the finite analysis

$P_{\mathrm{u}, \mathrm{a}} \quad$ Ultimate shear resistance of specimen in theoretical analysis

$T \quad$ Prestressing force acting on the bolt

a Gap between the bolt and hole in faceplate

$d \quad$ Diameter of bolts

$h \quad$ Depth of the C-channel

$f_{c} \quad$ UHPC compressive strength

$f_{\mathrm{t}} \quad$ UHPC ultimate tensile strength;

$f_{\mathrm{u}} \quad$ the ultimate strength of C-channel.

$r \quad$ Diameter of bolt hole

$t_{\mathrm{f}} \quad$ Thickness of flange

$t_{\mathrm{w}} \quad$ Web thickness

$\Delta \quad$ Slip

$\triangle_{\mathrm{a}} \quad$ Slip at $P_{\mathrm{u}}$

$\Delta_{\mathrm{a}, \mathrm{T}} \quad$ Experimental slip at $P_{\mathrm{u}}$

$\Delta_{\mathrm{a}, \mathrm{FE}} \quad$ Numerical slip at $P_{\mathrm{u}}$

$\Delta_{\mathrm{u}} \quad$ Slip capacity of ECs

$\Delta_{\mathrm{u}, \mathrm{T}} \quad$ Test slip capacity of ECs

$\Delta_{\mathrm{u}, \mathrm{FE}} \quad$ FE slip capacity of ECs

$\varepsilon_{\mathrm{c} 0} \quad$ Strain at $f_{\mathrm{c}}$

$\varepsilon_{\mathrm{t} 0} \quad$ Strain at $f_{\mathrm{t}}$

$\varepsilon_{\mathrm{i}, \mathrm{pl}} \quad$ Plastic strains at point $i$

$\varepsilon_{\mathrm{F}, \mathrm{pl}} \quad$ Plastic strains at fracture point

$\varepsilon_{\mathrm{R}, \mathrm{pl}} \quad$ Plastic strains at rupture point

$\varepsilon_{F \text {,shear }}^{\mathrm{pl}}$ Initiation ratios of shear damage

$\varepsilon_{\text {nom }}$ Nominal strain

$\varepsilon_{\text {true }} \quad$ True strain of steel materials

$\varepsilon_{0, \mathrm{pl}} \quad$ The uniaxial damage initiation strain

$\bar{\varepsilon}_{0, p l}$ Three-dimensional damage initiation strain of steel material

$\bar{u}_{\mathrm{i}, \mathrm{pl}} \quad$ Equivalent plastic displacement 
$\theta \quad$ Stress triaxiality of the steels

$\rho \quad$ Prestressing ratio of the externally connected bolt

$\sigma_{i} \quad$ Engineering stress at $i$

$\bar{\sigma}_{i} \quad$ True stress at $i$

$\sigma_{\text {nom }} \quad$ Nominal stress

$\sigma_{\text {true }}$ True stress curves of steel materials

$\sigma_{\mathrm{y}}, \sigma_{\mathrm{u}}$ Yield and ultimate strength of bolts

\section{Acknowledgment}

The authors would like to acknowledge the financial supports by Science Project of Tianjin Municipal Education Commission (No.2019KJ122). The authors gratefully express their gratitude for the financial supports.

\section{References}

[1] Montague P., "A simple composite construction for cylindrical shells subjected to external pressure", J Mech. Eng. Sci., 17 (2), 105-113, 1975.

[2] Solomon S.K., Smith D.W., Cusens A.R., "Flexural tests of steel-concrete-steel sandwiches", Mag. Concr. Res., 28 (94), 13-20, 1976.

[3] Lin M., Lin W., Wang Q., Wang X., "The deployable element, a new closure joint construction method for immersed tunnel", Tunn. Undergr. Sp. Tech., 80, 290-300, 2018.

[4] Foundoukos N., Xie M., and Chapman J.C., "Behaviour and design of steel-concrete-steel sandwich construction", Adv. Steel Constr., 4(2), 123-133, 2008.

[5] Yan J.B., Chen A.Z., Wang T., "Developments of double skin composite walls using novel enhanced C-channel connectors", Steel Compos. Struct., 33(6) 877-889, 2019

[6] Zhang W.J., Koizumi A., "Behavior of composite segment for shield tunnel", Tunn. Undergr. Sp. Tech., 25 (4), 325-332, 2010.

[7] Yan J.B., Liew J.Y.R., Zhang M.H., "Shear-tension interaction strength of J-hook connectors in steel-concrete-steel sandwich structure", Adv. Steel Constr., 11(1), 72-93, 2015.

[8] Yan J.B., Liu X.M., Liew J.Y.R., Qian X., Zhang M.H., "Steel-concrete-steel sandwich system in Arctic offshore structures: materials, experiments, and design", Mater. Design., 91, $111-121,2016$

[9] Yan J.B., Wang Z., Wang X., "Behaviour of steel-concrete-steel sandwich plates under different ice-contact pressure", Adv. Steel Constr., 15(1), 116-122, 2019

[10] Lin Y.Z., Yan J.C., Cao Z.G., Zeng X.Z., Fan F., Zou C.Y., "Ultimate strength behaviour of S-UHPC-S and SCS sandwich beams under shear loads", J. Constr. Steel Res., 149, 195-206, 2018.

[11] Yan J.B., Chen A.Z., Guan H.N., Wang T., "Experimental and numerical studies on ultimate strength behaviour of SCS sandwich beams with UHPFRC", Constr. Build. Mater., 256,
119464, 2020.

[12] Marshall P.W., Palmer A.C., Liew J.Y.R., Wang T.Y., Thein M.K.W., "Bond Enhancement for Sandwich Shell Ice Wall", International Conference and Exhibition on Performance of Ships and Structures in Ice, 20-23, 2010

[13] Yan J.B., Liew J.Y.R., Zhang M.H., Sohel K.M.A., "Experimental and analytical study on ultimate strength behaviour of steel-concrete-steel sandwich composite beam structures", Mater. Struct., 48(5), 1523-1544, 2015.

[14] Ji X., Cheng X., Jia X., Varma A.H., "Cyclic in-plane shear behavior of double-skin composite walls in high-rise buildings. ASCE J. Struct. Eng., 143 (6), 04017025, 2017.

[15] Xie M., Foundoukos N., Chapman J.C., "Experimental and numerical investigation on the shear behaviour of friction-welded bar-plate connections embedded in concrete", J. Constr. Steel Res., 61, 625-649, 2004.

[16] Kolsters H., Wennhage P., "Optimisation of laser welded sandwich panels with multiple design constraints. Mar. Struct., 22(2), 154-171, 2009.

[17] Yan J.B., Li Z.X., Wang T., "Seismic behaviour of double skin composite shear walls with overlapped headed studs", Constr. Build. Mater., 191, 590-607, 2018.

[18] Chen L., Wang S., Lou Y., Xia D., "Seismic behavior of double-skin composite wall with Lshaped and C-shaped connectors", J. Constr. Steel Res., 160, 255-270, 2019.

[19] Yan J.B., Hu H.T., Wang T., "Shear behaviour of novel enhanced C-channel connectors in steel-concrete-steel sandwich composite structures", J. Constr. Steel Res., 166, 105903, 2020.

[20] Yan J.B., Guan H.N., Wang T., "Steel-UHPC-steel sandwich composite beams with nove enhanced C-channel connectors: Tests and analysis", J. Constr. Steel Res., 170, 106077, 2020.

[21] Yan J.B., Guan H.N., Wang T., "Numerical studies on steel-UHPC-steel sandwich beams with novel enhanced C-channels", J. Constr. Steel Res., 170, 106070, 2020.

[22] Yan J.B., Chen A.Z., Wang T., "Compressive behaviours of steel-UHPC-steel sandwich composite walls using novel EC connectors", J. Constr. Steel Res., 173, 106244. 2020.

[23] Zhu J.S., Wang Y.G., Yan J.B., "Shear behaviour of steel-UHPC composite beams in waffle bridge deck", Compos. Struct., 234, 111678, 2020

[24] ABAQUS. ABAQUS Standard User's Manual, Version 6.12, RI (USA): Dassault Systemes Corp, Providence, 2012

[25] Yan J.B., Qian X., Liew J.Y.R., Zong L., "Damage plasticity based numerical analysis on steel-concrete-steel sandwich shells used in the Arctic offshore structure", Eng. Struct., 117, 542-559, 2016.

[26] Yan J.B., Zhang W., "Numerical analysis on steel-concrete-steel sandwich plates by damage plasticity model: From materials to structures", Constr. Build. Mater., 149,801-815, 2017.

[27] Lee J., Fenves G.L., "Plastic-damage model for cyclic loading of concrete structures", J. Eng Mech. ASCE, 124(8), 892-900, 1998

[28] Eurocode 4 (2004). EN 1994-1-1-Design of composite steel and concrete structures. Part 1.1, General rules and rules for buildings, BS.

[29] Yan J.B., Hu H.T., Wang T., "Shear behaviour of enhanced C-channel connectors in double skin composite structures with UHPC", Structures, 31, 266-285, 2021. 